\title{
1 Simultaneous acoustic monitoring uncovers evidence of 2 biodiversity loss and overlooked temporal variation in a 3 threatened Amazonian bird community
}

4

\author{
W. Alexander Hopping ${ }^{1}$, Holger Klinck ${ }^{1}$
}

${ }^{1} \mathrm{~K}$. Lisa Yang Center for Conservation Bioacoustics, Cornell Lab of Ornithology, Cornell University, Ithaca, NY, USA

Corresponding Author:

W. Alexander Hopping ${ }^{1}$

Email address:wah63@cornell.edu

2. We employed an array of ten autonomous recording units (ARUs) spanning edge, degraded, and interior forest at a reserve on the deforestation frontier of Madre de Dios, Peru, a region featuring some of the richest, most complex avian assemblages on Earth. Recordings from 21 dawn-hours across three days at seven sites were manually annotated by a single observer.

3. ARUs and manual annotation performed well as an inventory method, especially for midstory and understory species. Sites in edge and degraded habitats featured significantly lower avian species richness, Shannon diversity, and vocal activity levels than in the forest interior, patterns that replicate the findings of prior high-effort avian censuses in the region. We observed significant temporal variation between days; at all featured sites, vocal activity was highest on January $20^{\text {th }}$ and lowest on January $31^{\text {st }}$.

4. We demonstrated that novel annotation-generated metrics can work as effective proxies for abundance data and per-capita song rate, correlating with diversity indices and efficiently 
characterizing habitats at a level of detail unobtainable with human observers. Generalist species were significantly overrepresented in the soundscapes of interior forest, relative to their contributed share of species richness, and interior specialists were underrepresented, suggesting that the entire 191 ha site is degraded. The between-days temporal variation that we documented, almost certainly overlooked without simultaneous monitoring, may obfuscate or distort the results of traditional surveys.

5. Synthesis \& Applications. We propose that PAM should become a cornerstone of biodiversity research. The standardization advantages demonstrated in this study, permanent storage, multi-taxa applications, and potential of automated identification make bioacoustics an ideal methodological avenue for guiding management and policy under rapid global change.

Keywords: avian biodiversity, bioacoustics, deforestation and degradation, edge effects, fragmentation, passive acoustic monitoring, Peruvian Amazon, spatiotemporal variation.

\section{Introduction}

The tropics account for an overwhelming share of Earth's biodiversity, featuring more than $75 \%$ of all species and over $90 \%$ of terrestrial birds (Barlow et al. 2018). Of particular importance is the Amazon basin, the largest intact tropical system on the planet (Allan et al. 2017) and the epicenter of global biodiversity (Jenkins et al. 2013). Like most of the tropics, the Amazon is undergoing major ecological change (Edelman 2014), primarily from the region's rapidly expanding anthropogenic land use footprint (Laurence et al. 2014), as well as the increasing impacts of climate change (Lovejoy 2013). Despite their importance, however, the tropics are largely neglected in biodiversity, and ecosystem function literature (Wilson et al. 2016), and assumptions derived from studies in temperate regions have been erroneously used to characterize tropical systems where they do not apply (Clarke et al. 2017). If we are to meet the international community's sustainable development goals, more biodiversity research focused specifically on tropical systems is necessary (United Nations 2015).

Land use change in Amazonia, primarily the result of agriculture, mining, and expanding road networks, is the most significant threat to biodiversity in the basin (Laurance et al. 2014) and likely an underestimated driver of climate change (Mahowald et al. 2017), compounding the importance of its study. In Madre de Dios, Peru, these pressures have driven accelerated rates of deforestation, fragmentation, and degradation over recent decades, making the region a global deforestation hotspot (Nicolau et al. 2019, Sánchez-Cuervo et al. 2020), and inducing ecosystem decay and biodiversity loss in remaining habitat patches (Canaday \& Rivadeneyra 2001, 
Laurance et al. 2002, Haddad et al. 2015, Stouffer 2020), but the full impacts of these changes remain unknown. Várzea floodplain forest, the focus of this study, is particularly vulnerable to these dynamics due to its limited distribution, easy access from river-based transport, and high concentration of endemic bird species, many of which are restricted to particular successional stages in this forest type (Foster et al. 1994, Robinson \& Terborgh 1997). Even in intact Amazonian systems, long-term studies have recently uncovered baseline shifts and population declines in avian communities, perhaps due to climate change (Blake \& Loiselle 2015, Stouffer et al. 2020). However, such assessments are complicated by the difficulty of tropical field surveys, leading to flawed baseline species occurrence data (Boakes et al. 2010, Lees et al. 2014, Robinson et al. 2018) and overlooked biodiversity losses in Amazonia (Socolar et al. 2019), which interfere with conservation efforts in the region.

Birds, which are generally accessible, identifiable, and better understood than other Neotropical groups, are presently the most cost-effective study taxa for monitoring Amazonian biodiversity (Gardner et al. 2008, Lees et al. 2014). Birds are ubiquitous and can be highly responsive to habitat conditions, making them excellent proxies for understanding ecosystem health and global change (Remsen 1994, Blackburn \& Gaston 1998, Bibby 1999). Despite these advantages, the Amazon's avifauna remains poorly documented and subject to significant knowledge gaps (Barlow et al. 2011, Lees et al. 2014). While high-quality, standardized, scalable data on birds and other taxonomic groups is necessary for guiding conservation priorities in the tropics, such data are difficult to generate with traditional survey methods. Overwhelming avian species richness, including many rare and similar species, challenging logistics, and poor viewing conditions typical of dark, densely vegetated rainforest interiors (Fig. 1) contribute to the unreliability of avian surveys in Amazonia, where upwards of $95 \%$ of birds are heard but never seen by a field observer (Robinson et al. 2018). Amazonian soundscapes include thousands of vocalization types, inducing high rates of false-negative and false-positive identification errors (Remsen 1994), and it can take months for skilled observers to reach a comfort level attainable in just one to two weeks of field experience in temperate systems (Parker 1991). Additionally, neotropical soundscapes are subject to high levels of spatiotemporal heterogeneity, with species singing in narrow time windows (Parker 1991, Hart et al. 2015), at seasonally variable rates (Blake 1992), and as a function of fine-grain floristic, geographic, and spatial variables, which are still poorly understood (Menger et al. 2017). As a result, studies relying on point counts and other non-simultaneous survey methods in Amazonia may require substantial sample sizes, which are often infeasible to obtain (Esquivel \& Peris 2008, Rodriguez et al. 2014). 


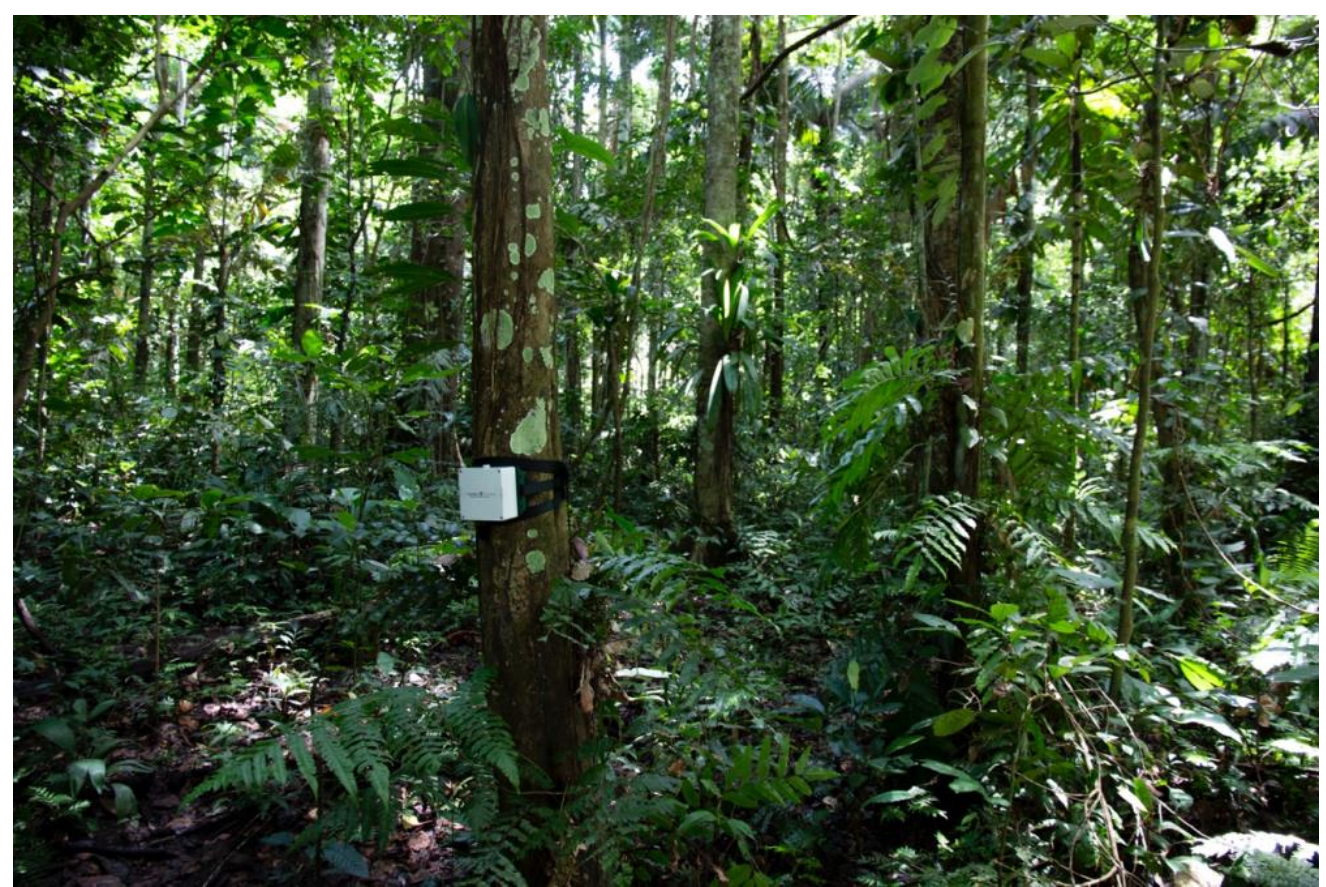

Figure 1: Site 07, typical várzea habitat in the reserve.

Autonomous Recordings Units (ARUs) effectively address many of the shortfalls of traditional point counts in tropical systems. Simultaneous and continuous monitoring of many locations has the capacity to completely eliminate temporal bias in surveys (Venier et al. 2012, Tegeler et al. 2012), data collection is independent of observer skill level, and permanent records can be reviewed, distributed, and verified by experts at will, enabling independent verification, reducing identification errors (Rempel et al. 2005, Rempel et al. 2019), and serving as ecological time capsules (Sugai \& Llusia 2019). ARUs can generate significantly greater data volume than traditional methods without increasing field time or cost (Hobson et al. 2002, Acevedo \& Villanueva-Rivera 2006, Tegeler et al. 2012), and bioacoustic data contains vocalizations of nontarget taxa and other soundscape elements, opening the door for more holistic research (Newson et al. 2017), while studies focused exclusively on birds can come at the expense of developing knowledge of other groups (Gardner et al. 2008). Human presence in the field during survey periods, which can bias results, is unnecessary (Jorge et al. 2018), and habitat structure influences bioacoustic surveys less than point counts (Darras et al. 2018). Perhaps most importantly, acoustic data introduces the possibility of automated detection and identification, which would have a transformative impact on biodiversity monitoring (Kahl et al. 2020). ARUs provide equivalent or superior data to point counts, especially in tropical forests like the Amazon, where the number of experienced observers is limited, access is difficult, the vast majority of species are best detected aurally, and sites are highly heterogenous over space and time (Haselmayer \& Quinn 2000, Acevedo \& Villanueva-Rivera 2006, Cellis-Murillo et al. 2012, Shonfield \& Bayne 2017, Darras et al. 2018, Darras et al. 2019, Pillay et al. 2019, Blake 139 2021). 
Here, we used ARUs to explore spatiotemporal variation in avian species richness, Shannon diversity, vocal activity, and community composition between sites at a threatened Amazonian reserve. Situated $15 \mathrm{~km}$ east of the rapidly growing frontier town of Puerto Maldonado and adjacent to an unmarked road, Inkaterra Reserva Amazónica (ITRA), our study site, faces intense land use pressure (Fig. 2). Likely inducing compositional changes and biodiversity loss across the reserve (Canaday and Rivadeneyra 2001, Laurance et al. 2002, Stouffer 2020), these dynamics are expected to intensify in coming years (Bird et al. 2012), making high-quality, baseline bioacoustic data especially valuable. Additionally, fully annotated Amazonian dawn choruses are critical for training automated soundscape identification algorithms, for which this dataset has already been used (Kahl et al. 2020).

We asked three overarching questions in our analyses. (1) Performance of acoustic sampling: how well do ARUs document avian community structure within the reserve, and can acoustic data serve as a proxy for abundance data, replicating the results of historic census efforts in Amazonia? (2) Temporal analysis: was there significant temporal variation between days that non-simultaneous survey methods might overlook? (3) Spatial analysis: do differences in habitat type and quality, particularly between edge and interior habitats, significantly impact avian species richness, diversity, community composition, and vocal activity? Can bioacoustic data be used to efficiently characterize habitats, without relying on manual estimates of per-capita song rate?

\section{Materials \& Methods}

\subsection{Site Selection}

The data for this study was collected at Inkaterra Reserva Amazónica (ITRA) in the Madre de Dios Department of southeastern Peru (12³2'07.8" S, 6902'58.2" W). This 191 ha private reserve is located at an elevation of $\sim 200 \mathrm{~m}$ along the Madre de Dios River, directly across from the Reserva Nacional de Tambopata, in one of the most biodiverse regions on the planet (Foster et al. 1994) (Fig. 2). The habitat at ITRA primarily consists of várzea floodplain forest, the most endangered forest type in the southwestern Amazon (Phillips et al. 1994), interspersed with seasonally flooded Mauritia palm swamp forest. 

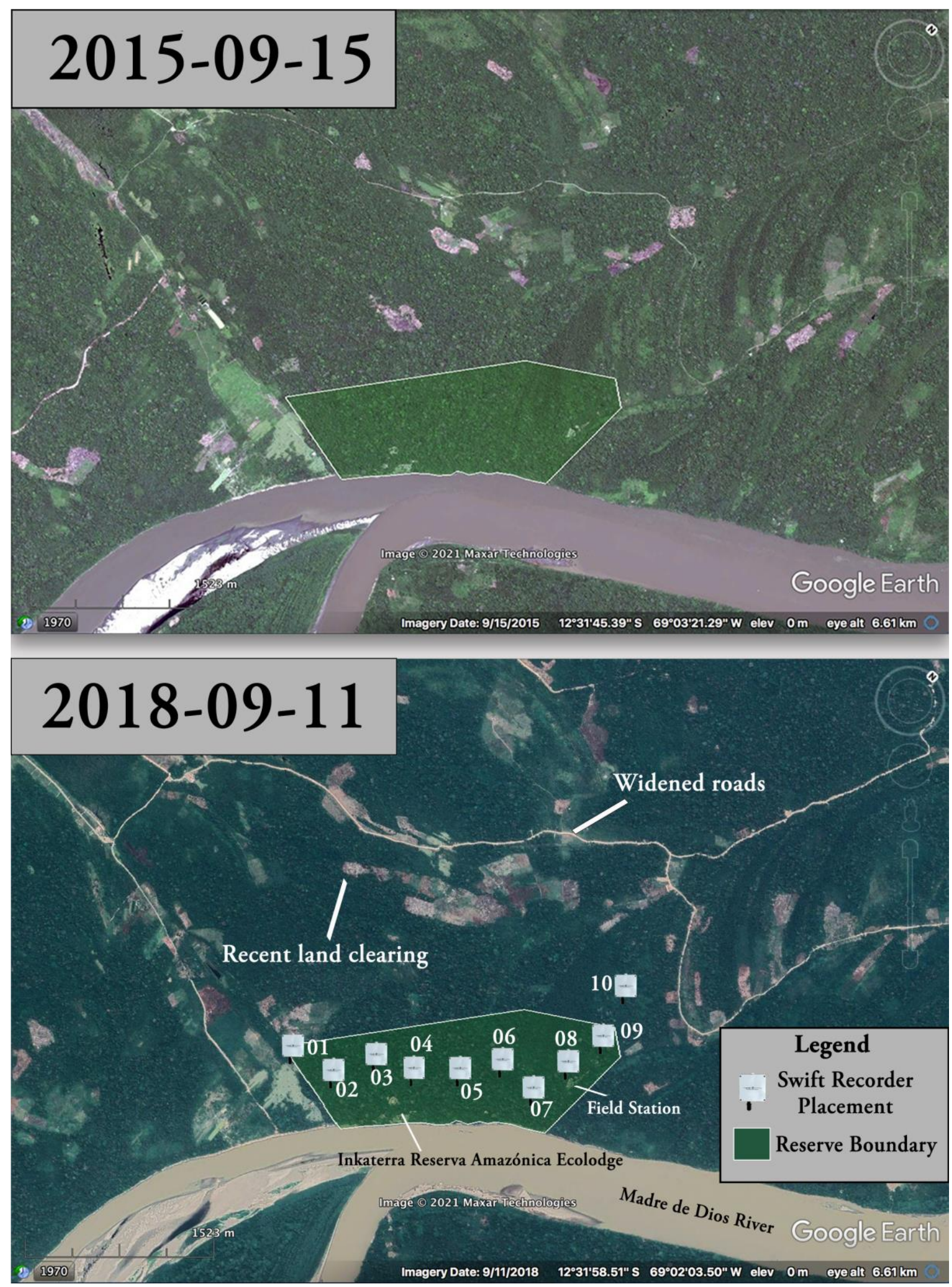

Figure 2: Swift recorder layout and progression of deforestation at the study site. Recorder placements covered 


\subsection{Data Collection}

Data were collected January 14-February 2, 2019, using ten ARUs (Swift recorder, K. Lisa Yang Center for Conservation Bioacoustics, Cornell Lab of Ornithology, Ithaca, NY, USA). ARUs were deployed across the entire reserve, at a minimum distance of $350 \mathrm{~m}$ from each other and $450 \mathrm{~m}$ from the river, to limit overlapping detection (pseudo-replication) and background noise (Ralph et al. 1995). Deployment locations were chosen to represent a gradient of intactness and forest habitat type, including edge (Site 01), degraded (Site 10), mature várzea in the reserve's interior (Site 04 and Site 06), and mixed palm swamp-várzea habitat (Site 02 and Site 05) (FIG. 2). Placed at a height of $1.5 \mathrm{~m}$ above the ground, the 10 ARUs recorded continuously (mono, WAV format) throughout the deployment using a sampling rate of $48 \mathrm{kHz}$ (16-bit resolution) and a gain setting of $35 \mathrm{~dB}$. The microphone sensitivity of the Swift was $-44 \mathrm{dBV} / \mathrm{Pa}$ $(+/-3 \mathrm{~dB})$ and featured a flat frequency response $(+/-3 \mathrm{~dB})$ in the frequency range of the vocalizations of interest. The clipping level of the analog-to-digital (ADC) converter was $+/-0.9$ $\mathrm{V}$.

\subsection{Acoustic Analysis (Annotation Process)}

Twenty-one total dawn-hours, from 05:00-06:00 PET (10:00-11:00 UTC), representing 7 of the 10 sites on three days, were manually annotated by the lead author using the Raven Pro Sound Analysis Software ${ }^{\circledR}$ (version 1.5; K. Lisa Yang Center for Conservation Bioacoustics, Cornell Lab of Ornithology, Ithaca, NY, USA). Six of these sites were used for analyses, two in each habitat type: fringe (edge and degraded), mixed, and várzea, with Site 08 excluded. For some analyses, mixed and várzea were grouped together as interior habitats. The three days, January 16 (Day A), January 20 (Day B), and January 31 (Day C), 2019, were randomly chosen from a subset of days that featured less than 5 minutes of heavy rain during the dawn-hour. The dawn-hour was selected because it contains the highest level of vocal activity and diversity among neotropical birds (Berg et al. 2006), including many species that only sing in narrow time windows around first light (Parker 1991, Blake 1992). Additionally, the dawn soundscape in Amazonia features far less anthropogenic activity and insect noise than other periods, reducing interference with avian species detection (Hart et al. 2015, Metcalf et al. 2020). $3 \mathrm{~dB}$ bandwidth $=100 \mathrm{~Hz}, 690 \mathrm{FFT}$ window size, 1024-sample DFT, 95\% temporal overlap). To reduce bias introduced by improved sound identification knowledge developed throughout the project, the order in which site days were annotated was determined using a random number generator. Vocalizations were labeled for both species and a handful of broader groups with confusing or indistinguishable calls, e.g., "TRSP" as "trogon species" (Trogonidae sp.). Background vocalizations, audible but not clearly visible on a spectrogram, were denoted with a ' 1 ' and excluded from most analysis. To account for inter-specific variation in call volume and 
215 frequency, consistency for applying 'background' designation was approached on a species-

216 specific basis. In cases where vocalizations from the same species were separated by fewer than

2175 seconds, they were included as part of the same annotation, while annotations were split if the

218 gap between vocalizations exceeded 5 seconds. An assortment of unlabeled sound clips,

219 featuring both identified and unidentified species, were sent to regional experts for secondary

220 verification. Annotations were reviewed repeatedly until unidentified vocalizations made up less

221

222

223

224

225

226

227

228

229

230

231

232

233

234

235

236

237

238

239

240

241

242

243

244

245

246

247

248

249

250

251

252

253

254 than $10 \%$ of the total avian vocal activity on a given recording. Considerable effort was made to accurately label as many foreground and background vocalizations as possible, with the goal of improving the value of this dataset for training soundscape-based automated identification algorithms.

\subsection{Statistical Analyses}

For each site, day, and individual recording, four metrics were calculated: species richness, Shannon diversity, vocal prevalence, and Bray-Curtis dissimilarity. Species richness and Shannon diversity were included as standard measures of ecological diversity (Okansen et al. 2019, Metcalf et al. 2020). Vocal prevalence (VP), the number of 15-second blocks in a recording containing at least one foreground vocalization from a species or taxa, was used to quantify vocal activity levels or soundscape abundance. Bray-Curtis dissimilarity was calculated between days, sites, and individual site days, ranging from 0 (no difference) to 1 (completely different).

Certain taxa were excluded from most analysis for data quality reasons: parrots (Psittacidae sp.), because they occurred almost exclusively as calling flyovers, along with Columbiformes (pigeons and doves) and three congeneric tinamou species, Cinereous Tinamou (Crypturellus cinereus), Little Tinamou (C. soui), and Bartlett's Tinamou (C. bartletti), which had overlapping vocalizations and were inconsistently identified with confidence. Non-species taxa were excluded from calculations of species richness and Shannon diversity but included in total vocal prevalence. Species were assigned to broad habitat-preference groups: interior (primary forest) specialists, edge (secondary forest) specialists, and generalists, based on the Birds of Peru field guide (Schulenberg et al. 2010), the Cornell Lab of Ornithology's Birds of the World (Billerman et al. 2020), and personal field experience (Supporting Information).

The scientific questions posed in the introduction were addressed as follows:

1: Performance of acoustic sampling. The list of species identified during this study was compared with data submitted from the reserve to the citizen science database eBird during the Dec-Feb season, over 13 years through 2020 (Sullivan et al. 2009). Because the relative utility of ARUs vs field observers varies across groups, species were placed in one of 10 guilds to facilitate more detailed comparisons: soaring raptors, hummingbirds, parrots, aerial insectivores 
(swallows and swifts), nocturnal species, open habitat specialists, aquatic habitat specialists (including flooded forest obligates), and canopy, midstory, and understory forest species. Correlation analysis (Pearson's $r$ ) was employed to assess the relationship between vocal prevalence, species richness, and Shannon diversity. Using vocal prevalence as a stand-in for abundance data, a rank-abundance curve was plotted and compared with the results of Terborgh et al. 1990, a historical high-effort census conducted in the region using mist-netting and point counts, to evaluate the performance of ARUs as an alternative to traditional approaches. The total number of species recorded was summarized in a table for each site and day, along with average species richness.

2: Temporal analysis. Paired T-tests were used to compare variation in species richness, Shannon diversity, and vocal prevalence across the three days, and to compare variation in BrayCurtis dissimilarity between parings of days.

3: Spatial analysis. Two-way repeated-measures ANOVA followed by Tukey's HSD tests for multiple comparisons were conducted in R (R Core Team, 2019), to assess differences in Shannon diversity, species richness, and vocal prevalence between habitat types. To evaluate whether or not community composition differed at edge sites compared to the forest interior, the Bray-Curtis dissimilarity between the edge Site (01) and all other sites was compared to the Bray-Curtis dissimilarity between non-edge sites. Relative soundscape representation (RSR) was assessed for each site day and habitat type by comparing the share of total vocal prevalence to the share of species richness contributed by habitat-preference groups. RSR has the potential to serve as a proxy for per-capita song rate, which is positively correlated with density and territory quality in birds (Pillay et al. 2019), therefore aiding in the characterization of habitat type and condition. Paired T-tests were used to assess the significance of representation. Patterns in community composition across sites were assessed using non-metric multidimensional scaling ordination (NMDS). NMDS analyses were calculated using the "bray" method and metaMDS function from the "vegan" package in R (Okansen et al. 2019), using vocal prevalence in place of abundance, for all species, interior specialists, and edge specialists, respectively. The NMDS ordinations were performed on two axes and checked to ensure that the output met minimum stress requirements (Kruskal 1964).

\section{Results}

\subsection{Summary Information}

We identified 134 species over 21 dawn-hours; 18,963 individual bounding-box annotations were drawn in Raven Pro, of which $94.8 \%$ were identified to the species or taxon level. At individual sites, the percent of total Vocal Prevalence that was not identified to a species or taxa group ranged from $4.1 \%$ (Site 06 ) to $7.1 \%$ (Site 02 ) between sites, and from $5.1 \%$ (Day C) to $5.4 \%$ (Day A) between days. Most annotations occurred in the frequency range 0.5-5 
$\mathrm{kHz}$, which features the highest diversity of Amazonian bird songs at dawn, and the least interference from insects, which contribute to significant signal masking between 4-12 kHz (Hart et al. 2015, Alvarez-Berríos et al. 2016, Aide et al. 2017, Metcalf et al. 2020). Seven species were recorded only as background vocalizations, and seven more were restricted to Site 08 , which was excluded from the majority of analysis because of sustained interference from a Mealy Parrot (Amazona farinose), which obscured other vocalizations on Day B and severely impacted overall detections at the site (Supporting Information).

Of the 120 foreground species detected outside of Site 08, two, Black-faced Antthrush (Formicarius analis) and Buff-throated Woodcreeper (Xiphorhynchus guttatus) were detected on all 18 site days, and six more were detected on at least two-thirds of site days. Most species were rare; more than half $(66,55 \%)$ were detected on 4 or fewer site days, and roughly a quarter (27, $23 \%$ ) on only a single recording (Fig. 3). In terms of total vocal prevalence, the most abundant species were Hauxwell's Thrush (Turdus hauxwelli), Black-faced Antthrush, and Thrush-like 310 Wren (Camplyothynchs turdinus), which were also the three most common species on eBird.

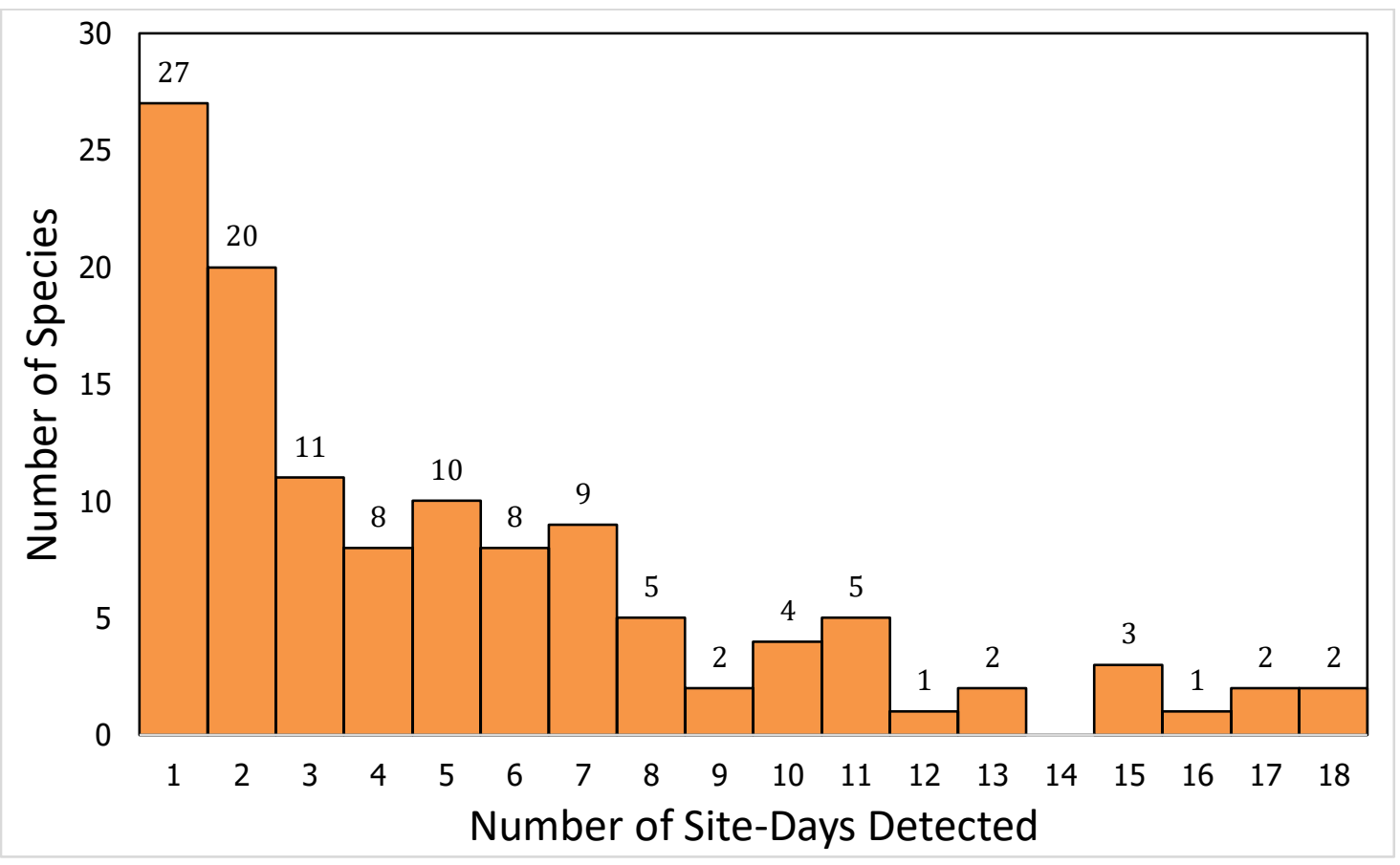

Figure 3: Number of site-days on which species were detected.

\subsection{Performance of Acoustic Sampling}

A total of 134 species were identified from recordings across all sites, including background vocalizations and species only detected at Site 08 . Through 2020, field observers in the reserve reported 360 species to the citizen science database eBird, spanning 253 complete checklists from December-February. Four species were detected exclusively with ARUs: 
Cinereous Mourner (Laniocera hypopyrra), Royal Flycatcher (Onychorhynchus coronatus), Striped Cuckoo (Tapera naevia), and Blue-crowned Manakin (Lepidothrix 11oronate), a first record for the reserve, bringing the total species list from both methods to 364 . Species reported on $>2 \%$ and $>5 \%$ of eBird checklists were considered "regular" and "expected," respectively, and the majority of species reported to eBird but missed by ARUs were neither (Table 1).

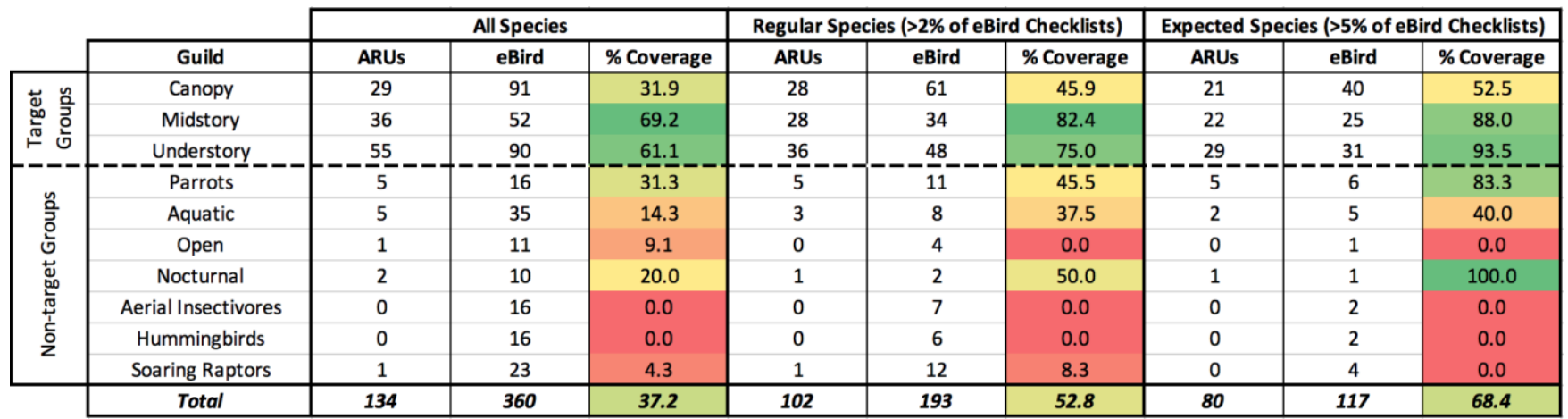

Table 1: Performance of ARUs vs eBird data by guild and rarity level. eBird detections are based on 253 complete checklists submitted within the reserve from December-February.

ARUs performed best with midstory and understory species, detecting $63 \%$ of all species in these foraging strata, including $91 \%$ of expected species, but were considerably less effective for canopy foragers, and, as expected, missed the vast majority of species in non-target groups (Table 1). There was a significant positive relationship between vocal prevalence and both species richness $(r=0.83, p=1.9 \mathrm{e}-05)$ and Shannon diversity $(r=0.75, p=3 \mathrm{e}-04)$ (Fig. 4). Using vocal prevalence as a stand-in for abundance, a rank-order curve was plotted; in line with the abundance-based results of Terborgh et al. (1990), we found that vocal prevalence was distributed equitably, fitting a log distribution $\left(R^{2}=0.84\right)$, with a high proportion of total vocal prevalence contributed by only a few species (Fig. 5).
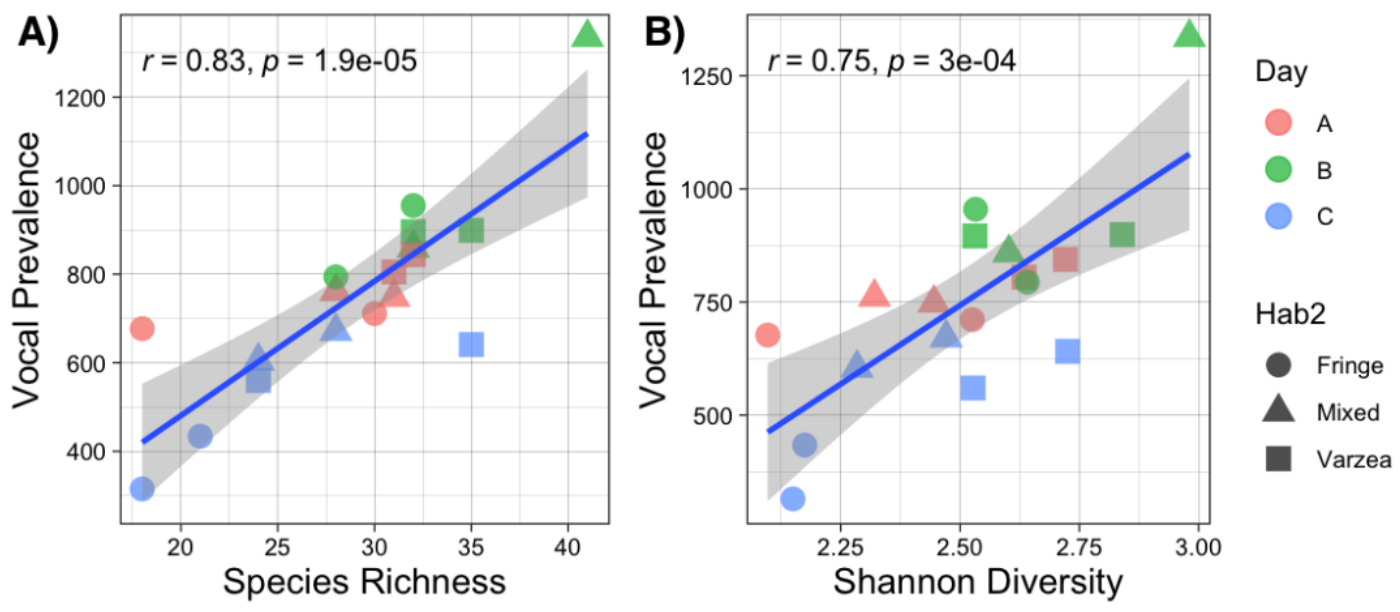

339 Figure 4: Vocal prevalence vs Species Richness (A) and Shannon Diversity (B). 

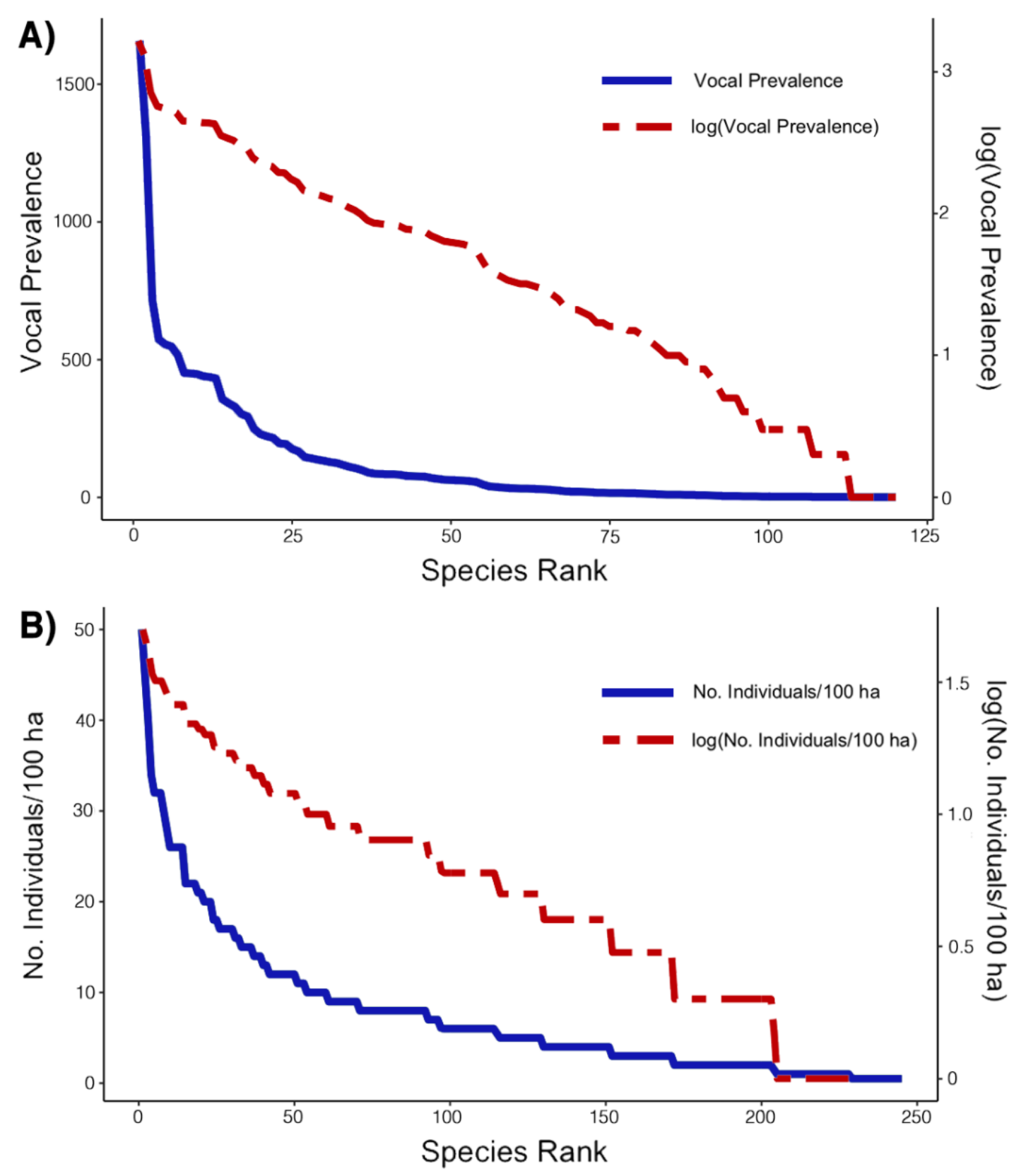

Figure 5: Rank-order curves for vocal prevalence (A), using our data, and no. individuals/100 ha (B), using the data from Terborgh et al. (1990), an avian census conducted with traditional methods over 12 person-months of effort at Cocha Cashu, another reserve in Madre de Dios.

\subsection{Temporal Variation}

We captured significant temporal variation in estimated avian species richness, Shannon diversity, vocal prevalence and inter-site community dissimilarity (Table 2). The three diversity and activity measures averaged highest on Day B, and temporal variation was especially consistent for vocal prevalence; at all six sites, vocal prevalence was highest on Day B and 
lowest on Day C. Paired t-tests found that Day B had significantly higher average species richness $(p=0.024)$, Shannon diversity $(p=0.015)$, and VP $(p=0.0027)$ than Day $\mathrm{C}$, which also had significantly lower average VP than Day A $(p=0.0026)$. Day B also featured consistently higher values than Day A for species richness $(p=0.094)$, Shannon diversity $(p=0.092)$ and VP $(p=0.059)$, but these results were not statistically significant. The compositional similarity between sites also differed across days; the average Bray-Curtis dissimilarity between Days A and B, 0.750, was significantly greater than the Bray-Curtis dissimilarity between Days A and C, $0.715(p=0.022)$, and between Days B and C, 0.710, $(p=0.044)$. The highest species total detected in an individual recording came from Site 02, Day B, which featured 41 species, $46 \%$ more than the 28 species identified at the site on Day A and C; adjacent Site 01 also featured significantly more species on Day B (32) than on Days A and C (18).

\begin{tabular}{c|ccccccc} 
Metric & Day & Total & Mean/pt & SE/pt & Range & Highest Site & Lowest Site \\
\hline Vocal Prevalence & A & 4546 & 757.7 & 25 & $677-844$ & Site 06 & Site 01 \\
& B & 5738 & 956.3 & 79 & $794-1335$ & Site 02 & Site 10 \\
& C & 3225 & 537.5 & 56 & $315-671$ & Site 02 & Site 01 \\
& & & & & & & \\
Species Richness & A & 57 & 27.5 & 2.1 & $18-32$ & Site 06 & Site 01 \\
& B & 78 & 33 & 1.9 & $28-41$ & Site 02 & Site 01 \\
& C & 56 & 25.7 & 2.5 & $18-35$ & Site 06 & Site 01 \\
& & & & & & & \\
& A & 3.50 & 2.46 & 0.084 & $2.10-2.72$ & Site 06 & Site 01 \\
& B & 3.57 & 2.69 & 0.068 & $2.53-2.98$ & Site 02 & Site 10 \\
& C & 3.26 & 2.39 & 0.084 & $2.15-2.73$ & Site 06 & Site 01
\end{tabular}

\section{Table 2: Summary of Temporal Variation}

\subsection{Spatial Variation}

Sites in fringe habitats averaged significantly lower species richness $\left(F_{1,14}=10.31, p=\right.$ $0.0063)$, Shannon diversity $\left(F_{1,14}=6.98, p=0.019\right)$, and vocal prevalence $\left(F_{1,14}=6.56, p=\right.$ 0.023 ) than interior sites (Table 3 ). Site 01 , in edge habitat, was the only site to feature significantly higher inter-site Bray-Curtis dissimilarity $(0.83)$ than the average between other sites $(0.66, p=2.2 \mathrm{e}-16)$ (Fig. 6 ), and NMDS ordination showed clustering of interior sites in 
bioRxiv preprint doi: https://doi.org/10.1101/2021.09.25.461815; this version posted September 26, 2021. The copyright holder for this preprint (which was not certified by peer review) is the author/funder, who has granted bioRxiv a license to display the preprint in perpetuity. It is made available under aCC-BY-NC-ND 4.0 International license.

\begin{tabular}{|c|c|c|c|c|c|c|c|c|c|}
\hline Metric & Site & Habitat & Total & Mean/day & SE/day & Range & Highest Day & Lowest Day & UnID\% \\
\hline \multirow[t]{6}{*}{ Vocal Prevalence } & 01 & Fringe & 1947 & 649 & 185.3 & $315-955$ & Day B & Day C & $6.5(206)$ \\
\hline & 10 & Fringe & 1939 & 646.3 & 108.8 & $434-794$ & Day B & Day C & 4.2 (119) \\
\hline & 02 & Mixed & 2767 & 922.3 & 208.0 & 677-1335 & Day B & Day C & $7.1(244)$ \\
\hline & 05 & Mixed & 2211 & 737 & 73.8 & 604-859 & Day B & Day C & $4.5(138)$ \\
\hline & 04 & Várzea & 2261 & 753.7 & 100.3 & $560-896$ & Day B & Day C & $5.2(154)$ \\
\hline & 06 & Várzea & 2384 & 794.7 & 78.5 & $641-899$ & Day B & Day C & $4.1(141)$ \\
\hline \multirow[t]{6}{*}{ Species Richness } & 01 & Fringe & 43 & 22.7 & 4.7 & $18-32$ & Day B & Day A/C & \\
\hline & 10 & Fringe & 42 & 26.3 & 2.7 & $21-30$ & Day A & Day C & \\
\hline & 02 & Mixed & 50 & 32.3 & 4.3 & $28-41$ & Day B & Day A/C & \\
\hline & 05 & Mixed & 49 & 29 & 2.5 & $24-32$ & Day B & Day A/C & \\
\hline & 04 & Várzea & 46 & 28 & 1.2 & $26-30$ & Day B & Day C & \\
\hline & 06 & Várzea & 55 & 34 & 1.0 & $32-35$ & Day B & Day A & \\
\hline \multirow[t]{6}{*}{ Shannon Diversity } & 01 & Fringe & 2.52 & 2.26 & 0.112 & $2.10-2.53$ & Day B & Day A & \\
\hline & 10 & Fringe & 2.65 & 2.45 & 0.115 & $2.17-2.64$ & Day B & Day C & \\
\hline & 02 & Mixed & 2.89 & 2.59 & 0.163 & $2.32-2.98$ & Day B & Day A & \\
\hline & 05 & Mixed & 2.64 & 2.44 & 0.075 & $2.28-2.60$ & Day B & Day C & \\
\hline & 04 & Várzea & 2.74 & 2.56 & 0.029 & $2.53-2.63$ & Day A & Day C & \\
\hline & 06 & Várzea & 3.02 & 2.76 & 0.032 & $2.72-2.84$ & Day B & Day A & \\
\hline
\end{tabular}

Table 3: Summary of Spatial Variation

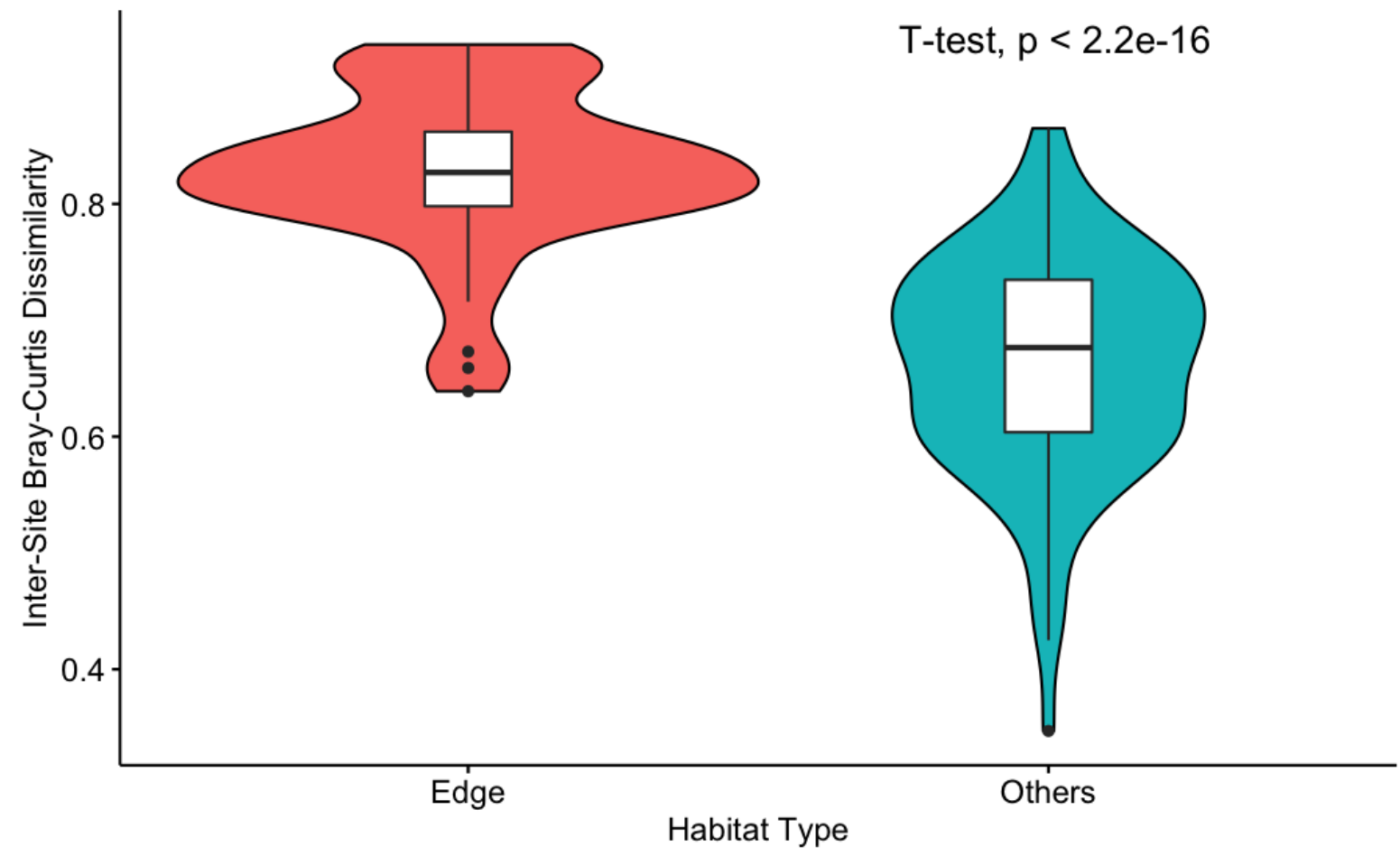

Figure 6: Bray-Curtis dissimilarity between the edge Site (01) and all other sites vs the Bray-Curtis dissimilarity between non-edge Sites. Same-site comparisons between days were excluded. 


\section{A) Interior (primary forest) specialists}

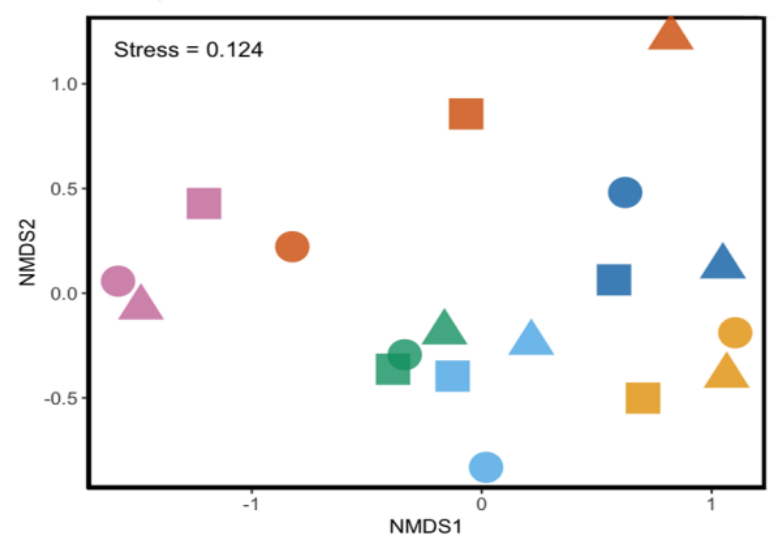

\section{B) Edge (secondary forest) specialists}

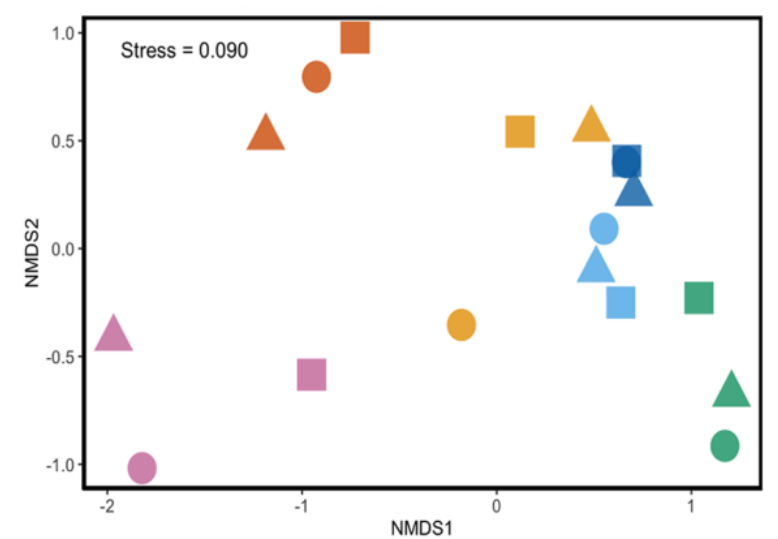

C) All species
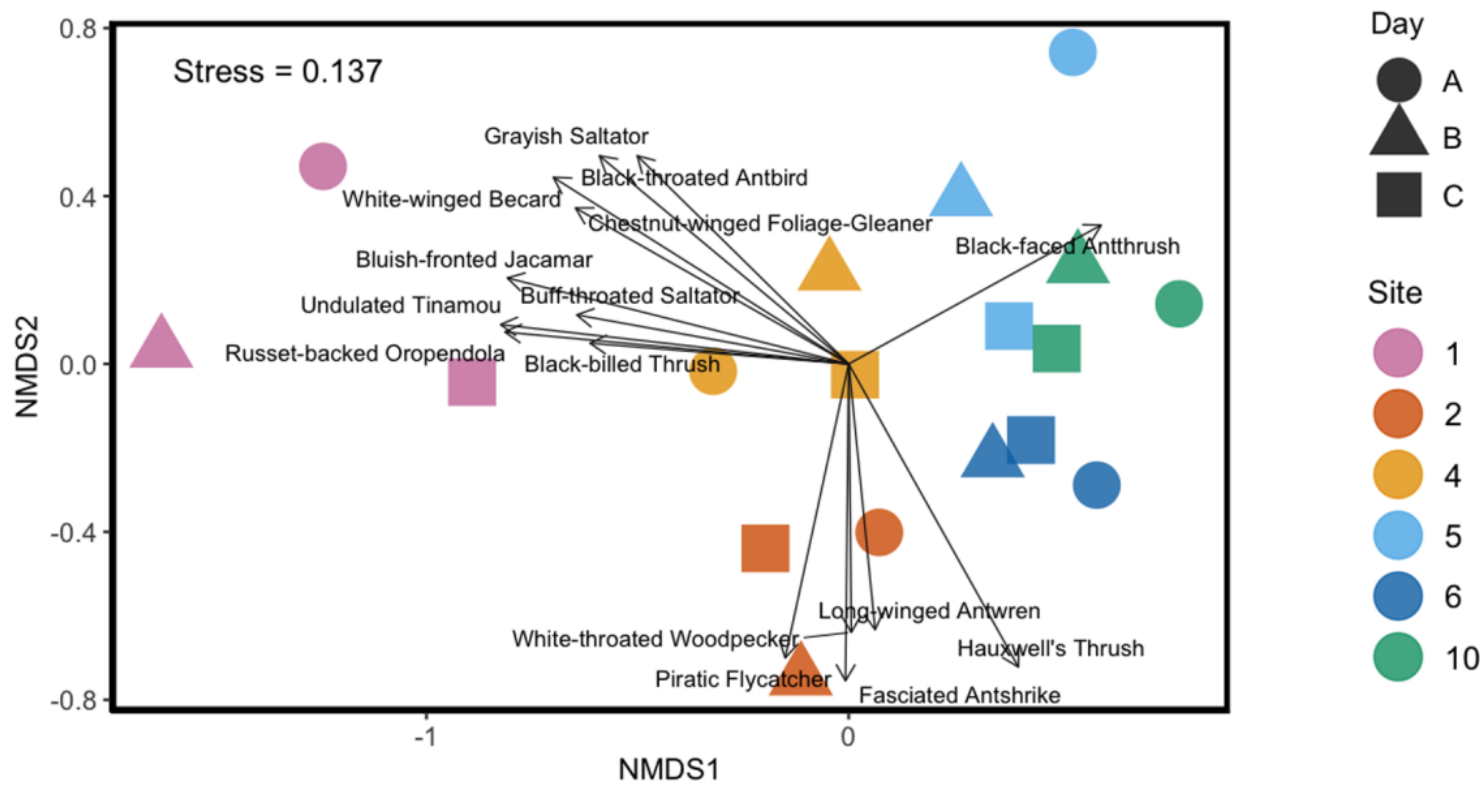

Site

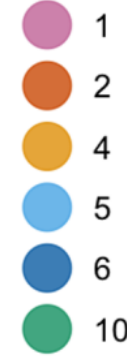

NMDS1

Figure 7: Nonmetric multi-dimensional scaling (NMDS) ordinations using Bray-Curtis dissimilarity, with vocal prevalence in place of abundance for interior specialists (A), edge specialists (B), and all species (C). Significantly representative species $(p<0.02)$ are shown with vectors on $(\mathrm{C})$.

Relative soundscape representation (RSR) (Fig. 8) indicated that interior specialists were significantly underrepresented as a share of vocal prevalence $(23.8 \%)$ relative to their share of overall species richness $(41.2 \%)$ across the reserve $(p=1.56 \mathrm{e}-06)$. While consistent across all habitat types, this effect was strongest in fringe habitats, where interior specialists made up $25.8 \%$ of average species richness but only $4.7 \%$ of average vocal prevalence $(p=5.28 \mathrm{e}-05)$, followed by mixed habitats $(\mathrm{S} \%=43.0, \mathrm{VP} \%=18.6, p=0.0011)$ and várzea $(\mathrm{S} \%=54.9, \mathrm{VP} \%$ $=48.1, p=0.74)$. Across all interior habitats, interior specialists made up $49 \%$ of species richness and $33.4 \%$ of VP $(p=0.0009)$. In contrast with interior specialists, generalists were relatively overrepresented in ITRA's soundscape, making up 38.7\% of average species richness and $51.5 \%$ of vocal prevalence across all site days $(p=0.0017)$. In fringe habitats, generalists 
were proportionally represented, making up $39.7 \%$ of species richness and $44.6 \%$ of VP, but they were significantly overrepresented in the soundscape of interior habitats, making up $38.2 \%$ of species richness and $55.0 \%$ of VP $(p=0.00054)$. Soundscape overrepresentation of generalists was strongest in mixed habitats, where they made up $64 \%$ of VP compared to $41.1 \%$ of species richness $(p=0.008)$. Generalists were also significantly overrepresented in the soundscape of várzea sites, accounting for $35.3 \%$ of species richness and $45.9 \%$ of VP $(p=0.02)$. Edge specialists made up $22.9 \%$ of VP and $17.3 \%$ of species richness across all sites, but this difference was not statistically significant $(p=0.10)$. In fringe habitats, however, edge specialists made up a significantly higher share of average vocal prevalence, $49.0 \%$, than species richness, $29.4 \%(p=0.012)$. Edge specialists contributed $11.2 \%$ of species richness and $9.8 \%$ of VP at interior sites.

405

\section{A) Interior (primary forest) specialists}

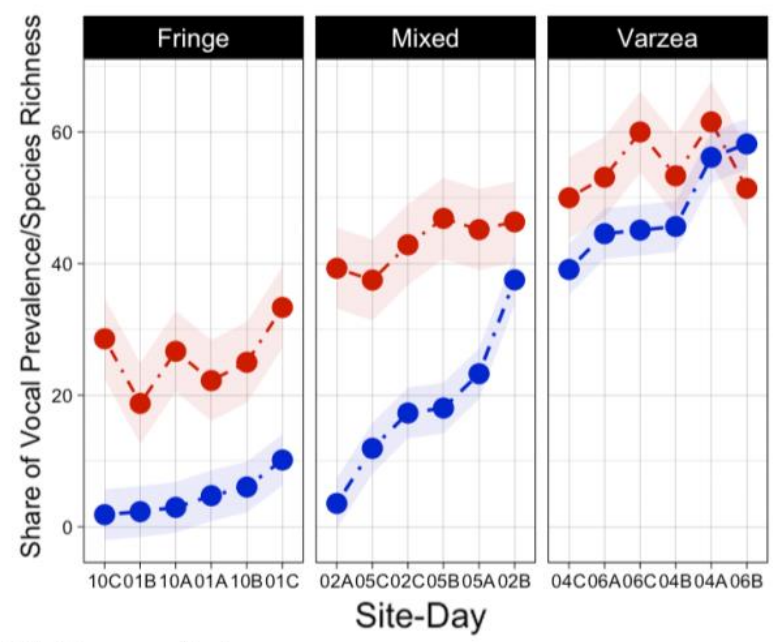

C) Generalists

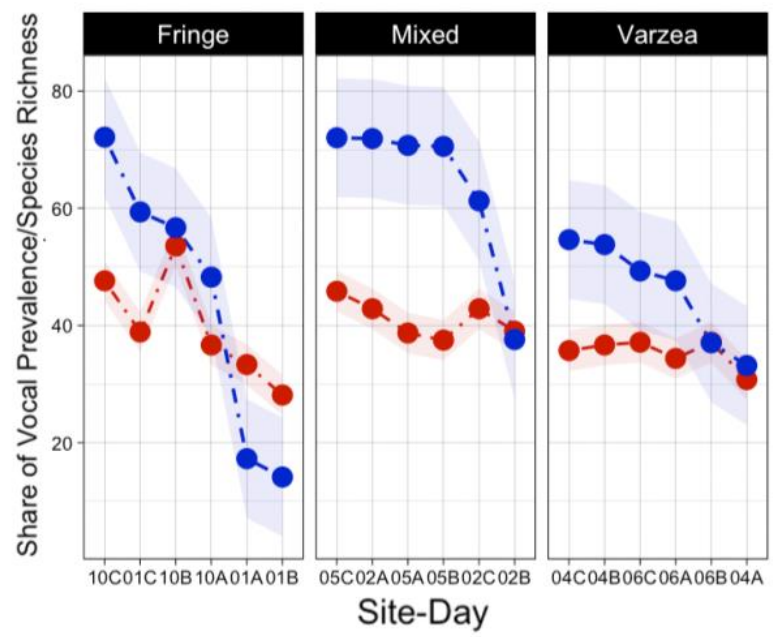

B) Edge (secondary forest) specialists

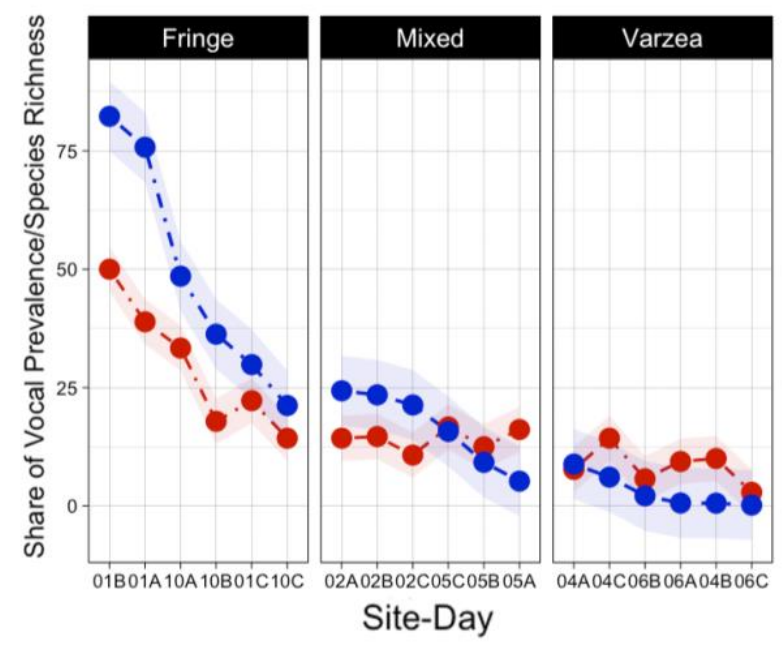

406

407

408

409
Figure 8: Relative soundscape representation (RSR) of interior (primary forest) specialists (A), edge (secondary forest) specialists (B), and generalists (C) by habitat type. Shaded areas represent one standard deviation of intrasite variation, averaged for each habitat preference group. 


\section{Discussion}

\subsection{Performance of Acoustic Sampling}

ARUs and manual annotation performed exceptionally well for understory and midstory species in the reserve, but was less effective for canopy foragers. With only 3 days of dawn recordings, we detected almost half $(27 / 63)$ of the rare $(<2 \%$ of checklists) midstory and understory species reported to eBird over 13 years, but only one of the 30 rare canopy species, Chestnut-winged Foliage-gleaner (Philydor erythropterum). The high-pitched calls of many Amazonian canopy-foraging passerines are extremely challenging to identify to species; even experienced observers are typically unable to use them as a primary identification method in the field. Such calls are poorly represented in acoustic databases like Xeno-canto and the Macaulay Library, making them even harder to learn. Additionally, detection of canopy species was almost certainly impacted by the $1.5 \mathrm{~m}$ average placement height of ARUs, especially in a region where canopy heights regularly exceed $30 \mathrm{~m}$ (Asner et al. 2014). Stevens et al. (2019) used ARUs at heights of 2-5m and documented decreased detection rates of canopy-dwelling mixed flock species relative to point counts, but found no such effects in habitats with shorter, smaller trees, supporting the idea that the distance between recorder and canopy height meaningfully influences detection rates of canopy species. Placing recorders in both the canopy and understory would likely improve the detection of species across multiple foraging strata (Bradfer-Lawrence et al. 2018, Darras et al. 2018, Castro et al. 2019). Including annotations from later in the morning is also likely to increase detection rates of canopy foragers, which are known to reach their vocal activity peak in the second or third hour after dawn, and time windows with lower activity would be easier to annotate (Blake 1992, Woltmann 2005, Esquivel \& Peris 2008).

Passive acoustic monitoring and manual annotation were an effective avian census method for the forest species that were the focus of this study, detecting $75 \%$ of the canopy, midstory, and understory species present on $>5 \%$ of the 253 December-February eBird checklists in only 21 hours of acoustic data (Table 1). The majority of missed species were rare at the study site or belonged to non-target groups, e.g., species of aquatic and open habitats. A larger sample of habitat types would capture more of these species, but we restricted our ARU placements for consistency. Detections of hummingbirds, aerial insectivores, and soaring raptors, which are primarily visual, are notoriously random in Amazonia and poorly suited for ARUs; only 8/55 $(15 \%)$ of these species were featured on more than $5 \%$ of eBird checklists at ITRA, mostly coming from open areas and the reserve's canopy tower, compared to 96/236 (41\%) of canopy, midstory and understory forest species. Additionally, soaring raptors and aerial insectivores have large foraging ranges and are observed primarily as flyovers, meaning that their detection rate can have more to do with visibility conditions than the characteristics of a site on the ground (Kułaga \& Budka 2019). As a result, flyover species are of only limited value for assessing differences between sites, and regularly excluded from general point count studies, even though their detectability is one of the biggest advantages of visual survey methods over ARUs (Ralph 
et al. 1995, Van Wilgenburg et al. 2017). Avian censuses in Amazonia typically find that a high percentage of species occupy only a small share of sites, which our results reinforced (Terborgh et al., 1990, Menger et al., 2017, Blake 2021) (Fig. 3). That 23\% (27/120) of the species in our study were featured on just one recording site, and $32 \%$ and $27 \%$ at one site and day, respectively, suggests that ARU performance should be expected to improve continuously over a larger sample (Wood et al. 2021). Annotating many short-duration time blocks, representing a broader range of temporal windows than contiguous dawn-hours, can reduce requisite analysis time or improve results, including higher detection rates of uncommon and rare species, more complete estimates of alpha and gamma diversity, and fewer false absences (Shonfield \& Bayne 2017, Metcalf et al. 2021).

Vocal prevalence correlated strongly with estimates of both species richness $(r=0.83, p$ $=1.9 \mathrm{e}-5)$ and Shannon diversity $(r=0.75, p=3 \mathrm{e}-4)$. VP is a better indicator of overall activity levels than raw call count, total number of annotations, or total annotation time, because it smooths out natural differences in vocalization patterns across species. While metrics that require species-level ID are highly contingent on observer skill level, driving inconsistencies in neotropical bird surveys (Robinson et al. 2018), total VP supports the use of broader taxonomic groups for challenging identifications, lowering time and experience barriers for researchers. Skill-driven variation in results from bioacoustic surveys is further reduced by the ability to replay, review, and distribute recordings to other experts, which is impossible to do with point counts. Substituting 'number of individuals/100 ha' with VP, we found that a rank-order curve of our data closely mirrored the results of Terborgh et al. (1990), a traditional, high-effort avian census conducted in Madre de Dios by skilled Neotropical field ornithologists (Fig. 5). This comparison validated the effectiveness of VP a proxy for abundance, enabling the calculation of abundance-based indices like Bray-Curtis dissimilarity and Shannon diversity with acoustic data.

\subsection{Temporal Variation}

We documented significant temporal variation between days, which was controlled for with simultaneous monitoring but could distort the results of traditional surveys. While temporal variation over the course of a morning is well documented in the tropics (Blake 1992, Woltmann 2005, Esquivel \& Peris 2008, Blake 2021), the variation that we observed between days was much greater and more consistent than expected. Though evident in all featured metrics, these effects were strongest and most uniform for VP, which was highest on Day B and lowest on Day $\mathrm{C}$ at all six sites. Day B was major outlier at adjacent Sites 01 and 02 , likely the result of a single large mixed flock that moved past both sites during the same hour. Plots comparing VP to Shannon diversity and species richness showed clear clustering by day (Fig. 4).

Stochastic vocal activity levels across days mean that temporal variation may obscure, or even exceed, differences in richness and diversity between sites and habitat types, complicating 
the interpretation of point count studies. That temporal variation was strongest for VP is relevant for point counts because aural detection probability for a field observer is a direct function of VP, which reflects the probability that a species vocalizes during a given 15 -s window. Standard duration point counts are much more likely to record false absences on days with lower total VP, even with static species presence. Esquivel \& Peris (2008) estimated that it would take four 10min visits per point, strategically spread out over different hours of the morning, to sufficiently cover the hourly variability in avian activity levels, even without considering variation between days, between different observers (Robinson et al. 2008), and travel time between sites. As a result, Amazonian point count studies seeking to do more than compile species lists may require sample sizes that are not practical, or risk drawing erroneous conclusions. surrounding dawn and dusk (Scott et al. 1986, Parker 1991, Metcalf et al. 2020, pers. obs.). These effects also apply to broader groups: for example, canopy species are known to reach their activity peak later in the morning than understory species (Blake 1992, Esquivel \& Peris 2008), and species with high sensitivity to habitat fragmentation may have proportionately higher detection rates in pre-dawn surveys than less sensitive species (Woltmann 2005). More detailed data on the specific temporal activity patterns of species and groups will be informative for selecting annotation windows, estimating avian presence/absence and abundance, and interpreting the results of point count studies. ARUs are uniquely suited for answering these questions, because their capacity for simultaneous monitoring can precisely quantify temporal variation between days, meaning that bioacoustic surveys can draw comparable conclusions with less field time and/or higher precision than point counts.

\subsection{Spatial Variation}

Intact forest outperformed edge and degraded sites ("fringe" habitats) in all featured diversity and activity metrics. On all three days, the edge Site (01) featured the lowest species richness, and the lowest values for vocal prevalence and Shannon diversity came from either Site 01 or Site 10, in degraded forest. These results are consistent with the findings of previously conducted Amazonian avian inventories using traditional methods, such as point counts and mist-netting (Terborgh et al. 1990, Laurence 2004), demonstrating the viability of ARUs as an alternative method. This habitat usage pattern differs from observed dynamics in temperate systems, where avian diversity tends to be higher in edge habitats than forest interiors (Baldi 1996, Lindell et al. 2007). Acoustic data is likely superior to point counts for comparing tropical habitat types with variable visibility conditions; visual detection rate is a direct function of vegetation density and other habitat characteristics, which can lead to relative overestimation of avian diversity and abundance in more open habitats (Kułaga \& Budka 2019), obscuring the magnitude of degradation-induced biodiversity loss in the tropics (Celis-Murillo et al. 2012, Darras et al. 2018, Darras et al. 2019). While sound transmission and auditory detection rate are 
530 also influenced by habitat structure, this impacts both point counts and acoustic monitoring (Darras et al. 2016, Castro et al. 2019). Mist-netting surveys are likewise impacted by habitat;

532 Karr (1981) found that capture rates of canopy-foraging bird species were higher in successional 533 habitats with low canopy heights than in tall primary forest (Remsen \& Parker 1983, Remsen 534 1996).

We found that relative soundscape representation (RSR), comparing the share of VP to the share of species richness contributed by habitat-preference groups, was a viable and significantly more efficient alternative to per-capita song rate. Bird species are known to vocalize more frequently in preferred habitats and where they are abundant (Pillay et al. 2019); song rate is used by females as an indicator of territory quality (Møller 1991, Gil \& Gahr 2002), is positively associated with density-dependent competition between males (Penteriani 2003, Goretskaia 2004), and may also increase conspecific immigration from surrounding areas (Fletcher 2007, Laiolo \& Tella 2008). While per-capita song rate can be calculated with ARUs through careful, manual analysis of individual variation between vocalizations (Pillay et al. 2019), doing so is labor-intensive and difficult to scale. Mirroring expected patterns for percapita song rates, RSR was highest in preferred habitats of both interior and edge specialists. Even in the reserve's most intact várzea forest, however, interior specialists made up a smaller share of VP than their share of species richness, and they were significantly underrepresented across all interior sites $(p=0.0009)$. Generalists, conversely, were overrepresented in the soundscapes of interior sites, an indicator of fragmentation; Amazonian fragments tend to disproportionately feature generalists, which possess strong dispersal abilities and high tolerance for deforested habitats (Sekercioglu et al. 2002, Lees \& Peres 2008). Site 01 was the only site to significantly differ in community composition compared to all other sites (Fig. 6). The lack of significant compositional differences between interior sites is another potential symptom of degradation; Burivalova et al. (2019) found that the soundscapes of selectively logged forests in Borneo were less heterogenous than the soundscapes of a never-logged forest, likely the result of subtractive homogenization. Together, the soundscape overrepresentation of generalists, soundscape underrepresentation of interior specialists, and relative compositional homogeneity of interior sites suggest that the entire 191 ha reserve is degraded, and in the process of becoming a fragment.

Edge effects are known to pervasively impact Amazonian bird communities and ecosystem function, stretching deep into forest interiors (Terborgh et al. 1990, Gascon et al. 2000, Laurence 2004, Barlow et al. 2006, Broadbent et al. 2008, Laurence et al. 2011, Whitworth et al. 2015, Wolfe et al. 2015, Haddad et al. 2015, Moura et al. 2016, Stouffer 2020), but we did not expect RSR to illustrate these dynamics so clearly. Based on its performance in this study, we suggest that RSR, which can only be calculated with ARUs, has the potential to be a useful, efficient tool for remotely characterizing habitat features and quality. RSR has applications for both long-term biodiversity monitoring and rapid assessment, without requiring 
570 established baseline data. Though frequently misrepresented as homogenous, Amazonian

571 habitats are highly heterogeneous (Pires \& Prance 1985, Tuomisto et al. 1995), and important

572 elements of their vegetational diversity remain poorly understood (Milliken et al. 2010, Macía

573 2011, Borges 2013). Interactions between habitat features and avian community structure in the

574 Amazon are extremely complex, influenced by variables like soil type (Borges 2013), riverine

575 sediment concentration (Laranjeiras et al. 2021), the condition of surrounding habitat (Stouffer

576 2006, Latta et al. 2011, Laurence et al. 2011, Woltmann 2012, Laurence et al. 2012, Wolfe et al.

577 2015, Barlow 2016, Menger et al. 2017, Hernández-Palma \& Stouffer 2018), the presence of

578 large animals (Redford 1992, Estes et al. 2011), and climate change (Blake \& Loiselle 2015,

579 Stouffer et al. 2020). As a result, Amazonian habitat assessments, which are generally reliant on

580 features discernable by field observers, can be overly simplistic. Under global change, RSR and

581 other approaches that assess nuanced habitats based on their use by species may be particularly

582 valuable.

583

\section{Synthesis \& Applications}

Developing a better understanding of the effects that deforestation, fragmentation, and degradation have on biodiversity in tropical biodiversity hotspots is a major international conservation priority (Gardner et al. 2008, Barlow et al. 2016, Stouffer 2020), particularly analyses that go beyond presence/absence and that can be applied at landscape scales (Hernández-Palma \& Stouffer 2018). The results of this study support the potential of simultaneous passive acoustic monitoring as a cornerstone of biodiversity assessment, for both birds and other taxa. We found that annotated acoustic data can replicate the results of historical avian censuses, characterizing community structure, species richness, Shannon diversity, and vocal activity levels across habitat types. We documented significant temporal variation between days, which may be missed with non-simultaneous survey methods, distorting their results.

Acoustic data can generate informative, novel metrics that are impossible to produce with human observers, including effective proxies for abundance data and per-capita song rate. Such metrics, namely VP and RSR, can efficiently characterize complex habitats based on species usage patterns, rather than relying on visible features. In the future, passive acoustic monitoring's scalability, permanent storage, and ability to integrate with new and developing technologies could have a transformative impact on global conservation efforts (Kahl et al. 2020). Rampant habitat destruction and climate change threaten to destabilize the Amazon basin, and long-term, perhaps cascading declines in biodiversity and ecosystem function have already been documented, even in structurally intact habitats (Bird \& Lees 2011, Laurence et al. 2012, Blake \& Loiselle 2015, Brienen et al. 2015, Lovejoy \& Nobre 2019, Stouffer 2020). If we wish to save, 608 bioacoustics should be a central research priority. 


\section{Authors' Contributions}

Both authors designed the methodology. H.K. helped to secure the funding to conduct the study; W.A.H. collected and annotated the recordings, analyzed the data, and led the writing of the manuscript. Both authors contributed critically to the drafts and gave final approval for publication.

\section{Acknowledgements}

We would like to thank the Inkaterra Association (ITA) staff for providing logistical support and excellent field station facilities, particularly Noe Huaraca, Dennis Osorio, and Kevin Jiménez Gonzales, who helped set up recorders. Noe, John Fitzpatrick, Fernando Angulo, Will Sweet, Ken Rosenburg, and Alex Wiebe helped identify unknown vocalizations, and Ken Rosenburg, Andrew Farnsworth, and Connor Wood provided comments on the draft. Viviana Ruiz-Gutierrez and Amanda Rodewald gave general guidance, and Sidd Srinivasan assisted with Python. Funding for equipment was provided by the K. Lisa Yang Center for Conservation Bioacoustics at the Cornell Lab of Ornithology, with support from Innóvate Perú, CORBIDI, and the Inkaterra Association. Travel expenses were funded by the Cornell Lab of Ornithology.

\section{Data Availability Statement}

All data collected is available on request and will be made publicly available upon acceptance.

\section{References}

Acevedo, M. A., \& Villanueva-Rivera, L. J. (2006). Using Automated Digital Recording Systems as Effective Tools for the Monitoring of Birds and Amphibians. Wildlife Society Bulletin, 34(1), 211-214. https://doi.org/10.2193/0091-7648(2006)34[211:uadrsa]2.0.co;2

Aide, T. M., Hernández-Serna, A., Campos-Cerqueira, M., Acevedo-Charry, O., \& Deichmann, J. L. (2017). Species richness (of insects) drives the use of acoustic space in the tropics. Remote Sensing, 9(11), 1-12. https://doi.org/10.3390/rs9111096

Allan, J. R., Venter, O., \& Watson, J. E. M. (2017). Temporally inter-comparable maps of terrestrial wilderness and the Last of the Wild. Scientific Data, 4, 1-8. https://doi.org/10.1038/sdata.2017.187 
Alvarez-Berríos, N., Campos-Cerqueira, M., Hernández-Serna, A., Delgado, C. J. A., Román-Dañobeytia, F., \& Aide, T. M. (2016). Impacts of small-scale gold mining on birds and anurans near the Tambopata Natural Reserve, Peru, assessed using passive acoustic monitoring. Tropical Conservation Science, 9(2), 832-851. https://doi.org/10.1177/194008291600900216

Asner, G. P., Anderson, C. B., Martin, R. E., Knapp, D. E., Tupayachi, R., Sinca, F., \& Malhi, Y. (2014). Landscape-scale changes in forest structure and functional traits along an Andes-to-Amazon elevation gradient. Biogeosciences, 11(3), 843-856. https://doi.org/10.5194/bg-11-843-2014

Baldi, A. (1996). Edge effects in tropical versus temperate forest bird communities: Three alternative hypotheses for the explanation of differences. Acta Zoologica Academiae Scientiarum Hungaricae, 42(3), 163-172.

Barlow, J., Peres, C. A., Henriques, L. M. P., Stouffer, P. C., \& Wunderle, J. M. (2006). The responses of understorey birds to forest fragmentation, logging and wildfires: An Amazonian synthesis. Biological Conservation, 128(2), 182-192. https://doi.org/10.1016/j.biocon.2005.09.028

Barlow, J., Ewers, R. M., Anderson, L., Aragao, L. E. O. C., Baker, T. R., Boyd, E., ... Gardner, T. A. (2011). Using learning networks to understand complex systems: A case study of biological, geophysical and social research in the Amazon. Biological Reviews, 86(2), 457-474. https://doi.org/10.1111/j.1469-185X.2010.00155.x

Barlow, J., Lennox, G. D., Ferreira, J., Berenguer, E., Lees, A. C., Nally, R. Mac, ... Gardner, T. A. (2016). Anthropogenic disturbance in tropical forests can double biodiversity loss from deforestation. Nature, 535(7610), 144-147. https://doi.org/10.1038/nature18326

Barlow, J., França, F., Gardner, T. A., Hicks, C. C., Lennox, G. D., Berenguer, E., ... Graham, N. A. J. (2018). The future of hyperdiverse tropical ecosystems. Nature, 559(7715), 517-526. https://doi.org/10.1038/s41586-0180301-1

Berg, K. S., Brumfield, R. T., \& Apanius, V. (2006). Phylogenetic and ecological determinants of the neotropical dawn chorus. Proceedings of the Royal Society B: Biological Sciences, 273(1589), 999-1005. https://doi.org/10.1098/rspb.2005.3410

Bibby, C. J. (1999). Making the most of birds as environmental indicators. Ostrich, 70(1), 81-88. https://doi.org/10.1080/00306525.1999.9639752

Billerman, S.M., Keeney, B. K., P. G. Rodewald, and T. S. Schulenberg (Editors) (2020). Birds of the World. Cornell Laboratory of Ornithology, Ithaca, NY, USA. https://birdsoftheworld.org/bow/home

Bird, J. P., \& Lees, A. C. (2011). Acknowledging an Amazon avifauna in crisis. Neotropical Birding, 11(July 2012), $74-77$.

Bird, J. P., Buchanan, G. M., Lees, A. C., Clay, R. P., Develey, P. F., Yépez, I., \& Butchart, S. H. M. (2012). Integrating spatially explicit habitat projections into extinction risk assessments: A reassessment of Amazonian avifauna incorporating projected deforestation. Diversity and Distributions, 18(3), 273-281. https://doi.org/10.1111/j.1472-4642.2011.00843.x

Blackburn, T. M., \& Gaston, K. J. (1998). Some methodological issues in macroecology. American Naturalist, 151(1), 68-83. https://doi.org/10.1086/286103 
Blake, J. G. (1992). Temporal Variation in Point Counts of Birds in a Lowland Wet Forest in Costa Rica. The Condor, 94(1), 265-275. https://doi.org/10.2307/1368816

Blake, J. G., \& Loiselle, B. A. (2015). Enigmatic declines in bird numbers in lowland forest of eastern Ecuador may be a consequence of climate change. PeerJ, 2015(8), 1-20. https://doi.org/10.7717/peerj.1177

700

Blake, J. G. (2021). Acoustic monitors and direct observations provide similar but distinct perspectives on bird assemblages in a lowland forest of eastern Ecuador. PeerJ, (January). https://doi.org/10.7717/peerj.10565

Boakes, E. H., McGowan, P. J. K., Fuller, R. A., Chang-Qing, D., Clark, N. E., O’Connor, K., \& Mace, G. M. (2010). Distorted views of biodiversity: Spatial and temporal bias in species occurrence data. PLoS Biology, 8(6). https://doi.org/10.1371/journal.pbio.1000385

Borges, S. H. (2013). Bird species distribution in a complex Amazonian landscape: Species diversity, compositional variability and biotic-environmental relationships. Studies on Neotropical Fauna and Environment, 48(2), 106-118. https://doi.org/10.1080/01650521.2013.841627

Bradfer-Lawrence, T., Gardner, N., \& Dent, D. H. (2018). Canopy bird assemblages are less influenced by habitat age and isolation than understory bird assemblages in Neotropical secondary forest. Ecology and Evolution, $8(11)$, 5586-5597. https://doi.org/10.1002/ece3.4086

Brienen, R. J. W., Phillips, O. L., Feldpausch, T. R., Gloor, E., Baker, T. R., \& Lloyd, J. (2015). This is a repository copy of Long-term decline of the Amazon carbon sink. White Rose Research Online URL for this paper : Version : Accepted Version Article : Brienen, RJW orcid . org / 0000-0002-5397-5755, Phillips, OL Longterm decline of the Amazon. Nature, 519(7543), 344-348.

Broadbent, E. N., Asner, G. P., Keller, M., Knapp, D. E., Oliveira, P. J. C., \& Silva, J. N. (2008). Forest fragmentation and edge effects from deforestation and selective logging in the Brazilian Amazon. Biological Conservation, 141(7), 1745-1757. https://doi.org/10.1016/j.biocon.2008.04.024

Burivalova, Z., Purnomo, Wahyudi, B., Boucher, T. M., Ellis, P., Truskinger, A., ... Game, E. T. (2019). Using soundscapes to investigate homogenization of tropical forest diversity in selectively logged forests. Journal of Applied Ecology, 56(11), 2493-2504. https://doi.org/10.1111/1365-2664.13481

Canaday, C., \& Rivadeneyra, J. (2001). Initial effects of a petroleum operation on Amazonian birds: Terrestrial insectivores retreat. Biodiversity and Conservation, 10(4), 567-595. https://doi.org/10.1023/A:1016651827287

Castro, I., De Rosa, A., Priyadarshani, N., Bradbury, L., \& Marsland, S. (2019). Experimental test of birdcall detection by autonomous recorder units and by human observers using broadcast. Ecology and Evolution, 9(5), 2376-2397. https://doi.org/10.1002/ece3.4775

Cellis-Murillo, A., Deppe, J., \& Ward, M. P. (2012). Evaluating the use of acoustic monitoring for surveying tropical birds. Journal of Field Ornithology, 83(2)(May 2012), 166-179. https://doi.org/10.2307/23256481

Clarke, D. A., York, P. H., Rasheed, M. A., \& Northfield, T. D. (2017). Does Biodiversity-Ecosystem Function Literature Neglect Tropical Ecosystems? Trends in Ecology and Evolution, 32(5), 320-323. https://doi.org/10.1016/j.tree.2017.02.012 
Darras, K., Pütz, P., Fahrurrozi, Rembold, K., \& Tscharntke, T. (2016). Measuring sound detection spaces for acoustic animal sampling and monitoring. Biological Conservation, 201, 29-37. https://doi.org/10.1016/j.biocon.2016.06.021

Darras, K., Batáry, P., Furnas, B., Celis-Murillo, A., Van Wilgenburg, S. L., Mulyani, Y. A., \& Tscharntke, T. (2018). Comparing the sampling performance of sound recorders versus point counts in bird surveys: A metaanalysis. Journal of Applied Ecology, 55(6), 2575-2586. https://doi.org/10.1111/1365-2664.13229

Darras, K., Batáry, P., Furnas, B. J., Grass, I., Mulyani, Y. A., \& Tscharntke, T. (2019). Autonomous sound recording outperforms human observation for sampling birds: a systematic map and user guide. Ecological Applications, 29(6). https://doi.org/10.1002/eap.1954

Edelman, A. et al. State of the Tropics: 2014 Report (James Cook Univ., Cairns, 2014).Available at: https://researchonline.jcu.edu.au/35471/1/SOTT_ExcecutiveSummary_Print1.pdf

Esquivel M., Alberto \& Peris, S. (2008). Influence of time of day, duration and number of counts in point count sampling of birds in an atlantic forest of Paraguay. Ornitologia Neotropical, 19(2), 229-242.

Estes, J. A., Terborgh, J., Brashares, J. S., Power, M. E., Berger, J., Bond, W. J., .. Wardle, D. A. (2011). Trophic downgrading of planet earth. Science, 333(6040), 301-306. https://doi.org/10.1126/science.1205106

Fletcher, R. J. (2007). Species interactions and population density mediate the use of social cues for habitat selection. Journal of Animal Ecology, 76(3), 598-606. https://doi.org/10.1111/j.1365-2656.2007.01230.x

Foster, R. B., Parker III, T. A., Gentry, A. H., Emmons, L. H., Chicchón, A., Schulenberg, T., ... Wust, W. (1994). The Tambopata-Candamo Reserved Zone of Southeastern Perú : A Biological Assessment Conservation Priorities : The Role of RAP. In Conservation Biology. Retrieved from https://www.conservation.org/docs/default-source/publication-pdfs/rap06_tambopata_candamo_peru_nov1994.pdf?Status=Master\&sfvrsn=72f3b47a_3

Gardner, T. A., Barlow, J., Araujo, I. S., Ávila-Pires, T. C., Bonaldo, A. B., Costa, J. E., .. Peres, C. A. (2008). The cost-effectiveness of biodiversity surveys in tropical forests. Ecology Letters, 11(2), 139-150. https://doi.org/10.1111/j.1461-0248.2007.01133.x

Gascon, C., Williamson, G. B., \& Da Fonseca, G. A. B. (2000). Receding forest edges and vanishing reserves. Science, 288(5470), 1356-1358. https://doi.org/10.1126/science.288.5470.1356

Gil, D., \& Gahr, M. (2002). The honesty of bird song: Multiple constraints for multiple traits. Trends in Ecology and Evolution, 17, 133-141. https://doi.org/10.1016/S0169-5347(02)02410-2

Goretskaia, Maria I. (2004). Song Structure and Singing Behaviour of Willow Warbler Phylloscopus in Populations of Low and High Density. Bioacoustics, (November 2012), 183-195. https://doi.org/10.1080/09524622.2004.9753524

Haddad, N. M., Brudvig, L. A., Clobert, J., Davies, K. F., Gonzalez, A., Holt, R. D., ... Townshend, J. R. (2015). Habitat fragmentation and its lasting impact on Earth's ecosystems. Science Advances, 1(2), 1-10. https://doi.org/10.1126/sciadv.1500052 
Hart, P. J., Hall, R., Ray, W., Beck, A., \& Zook, J. (2015). Cicadas impact bird communication in a noisy tropical rainforest. Behavioral Ecology, 26(3), 839-842. https://doi.org/10.1093/beheco/arv018

Haselmayer, J., \& Quinn, J. S. (2000). A comparison of point counts and sound recording as bird survey methods in amazonian southeast Peru. Condor, 102(4), 887-893. https://doi.org/10.2307/1370317

Hernández-Palma, A., \& Stouffer, P. C. (2018). Matrix and area effects on the nutritional condition of understory birds in Amazonian rainforest fragments. Perspectives in Ecology and Conservation, 16(3), 139-145. https://doi.org/10.1016/j.pecon.2018.06.003

Hobson, K. A., Rempel, R. S., Greenwood, H., Turnbull, B., \& Van Wilgenburg, S. L. (2002). Acoustic surveys of birds using electronic recordings: New potential from an omnidirectional microphone system. Wildlife Society Bulletin, 30(3), 709-720.

Jenkins, C. N., Pimm, S. L., \& Joppa, L. N. (2013). Global patterns of terrestrial vertebrate diversity and conservation. Proceedings of the National Academy of Sciences of the United States of America, 110(28), E2603-E2610. https://doi.org/10.1073/pnas.1302251110

Jorge, F. C., Machado, C. G., da Cunha Nogueira, S. S., \& Nogueira-Filho, S. L. G. (2018). The effectiveness of acoustic indices for forest monitoring in Atlantic rainforest fragments. Ecological Indicators, 91(August 2017), 71-76. https://doi.org/10.1016/j.ecolind.2018.04.001

Kahl, S., Clapp, M., Hopping, W. A., Goëau, H., Glotin, H., Planqué, R., Vellinga,W. P., Joly, A. (2020). Overview of BirdCLEF 2020: Bird sound recognition in complex acoustic environments. In: CLEF task overview 2020, CLEF: Conference and Labs of the Evaluation Forum, Sep. 2020, Thessaloniki, Greece.

Kahl, S., Wood, C. M., Eibl, M., \& Klinck, H. (2021). BirdNET: A deep learning solution for avian diversity monitoring. Ecological Informatics, 61(December 2020), 101236. https://doi.org/10.1016/j.ecoinf.2021.101236

Kułaga, K., \& Budka, M. (2019). Bird species detection by an observer and an autonomous sound recorder in two different environments: Forest and farmland. PLoS ONE, 14(2), 1-19. https://doi.org/10.1371/journal.pone.0211970

Laiolo, P., \& Tella, J. L. (2008). Social determinants of songbird vocal activity and implications for the persistence of small populations. Animal Conservation, 11(5), 433-441. https://doi.org/10.1111/j.14691795.2008.00202.x

Laranjeiras, T. O., Naka, L. N., Leite, G. A., Cohn-Haft, M. (2021). Effects of a major Amazonian river confluence on the distribution of floodplain forest avifauna, Journal of Biogeography, 48, 4, (847-860). https://doi.org/10.1111/jbi.14042

Latta, S. C., Tinoco, B. A., Astudillo, P. X., \& Graham, C. H. (2011). Patterns and magnitude of temporal change in avian communities in the ecuadorian andes. Condor, 113(1), 24-40. https://doi.org/10.1525/cond.2011.090252

Laurance, W. F., Lovejoy, T. E., Vasconcelos, H. L., Bruna, E. M., Didham, R. K., Stouffer, P. C., ... Sampaio, E. (2002). Ecosystem decay of Amazonian forest fragments: A 22-year investigation. Conservation Biology, 16(3), 605-618. https://doi.org/10.1046/j.1523-1739.2002.01025.x 
Laurance, S. G. W. (2004). Responses of understory rain forest birds to road edges in central Amazonia. Ecological Applications, 14(5), 1344-1357. https://doi.org/10.1890/03-5194

Laurance, W. F., Camargo, J. L. C., Luizão, R. C. C., Laurance, S. G., Pimm, S. L., Bruna, E. M., ... Lovejoy, T. E. (2011). The fate of Amazonian forest fragments: A 32-year investigation. Biological Conservation, 144(1), 56-67. https://doi.org/10.1016/j.biocon.2010.09.021

Laurance, W. F., Useche, D. C., Rendeiro, J., Kalka, M., Bradshaw, C. J. A., Sloan, S. P., .. Campbell, M. (2012). Averting biodiversity collapse in tropical forests. Nature, 489, 290-294.

Laurance, W. F., Sayer, J., \& Cassman, K. G. (2014). Agricultural expansion and its impacts on tropical nature. Trends in Ecology and Evolution, 29(2), 107-116. https://doi.org/10.1016/j.tree.2013.12.001

Lees, A. C., \& Peres, C. A. (2006). Rapid avifaunal collapse along the Amazonian deforestation frontier. Biological Conservation, 133(2), 198-211. https://doi.org/10.1016/j.biocon.2006.06.005

Lees, A. C., Naka, L. N., Aleixo, A., Cohn-Haft, M., Piacentini, V. de Q., Santos, M. P. D., \& Silveira, L. F. (2014). Conducting rigorous avian inventories: Amazonian case studies and a roadmap for improvement. Revista Brasileira de Ornitologia, 22(2), 107-120.

Lindell, C. A., Riffell, S. K., Kaiser, S. A., Battin, A. L., Smith, M. L., \& Sisk, T. D. (2007). Edge Responses of Tropical and Temperate Birds. The Wilson Journal of Ornithology, 119(2), 205-220. https://doi.org/10.1676/05-133.1

Lovejoy, T. (2013). Tropical forests under a changing climate and innovations in tropical forest management. Tropical Conservation Science, 6(3), 311-314. https://doi.org/10.1177/194008291300600301

Lovejoy, T. E., \& Nobre, C. (2019). Amazon tipping point: Last chance for action. Science Advances, 5(12), 4-6. https://doi.org/10.1126/sciadv.aba2949

Macía, M. J. (2011). Spatial distribution and floristic composition of trees and lianas in different forest types of an Amazonian rainforest. Plant Ecology, 212 (No. 7 (July 2011)), 1159-1177. https://doi.org/10.1007/s11258011-9895-1

Mahowald, N. M., Ward, D. S., Doney, S. C., Hess, P. G., \& Randerson, J. T. (2017). Are the impacts of land use on warming underestimated in climate policy? Environmental Research Letters, 12(9). https://doi.org/10.1088/1748-9326/aa836d

Menger, J., Magnusson, W. E., Anderson, M. J., Schlegel, M., Pe'er, G., \& Henle, K. (2017). Environmental characteristics drive variation in Amazonian understorey bird assemblages. PLOS ONE, 12(2), 1-20. https://doi.org/10.1371/journal.pone.0171540

Metcalf, O. C., Barlow, J., Devenish, C., Marsden, S., Berenguer, E., \& Lees, A. C. (2020). Acoustic indices perform better when applied at ecologically meaningful time and frequency scales. Methods in Ecology and Evolution, 2020(October), 1-11. https://doi.org/10.1111/2041-210x.13521 
Metcalf, O. C., Barlow, J., Marsden, S., Moura, N. G. De, Berenguer, E., Ferreira, J., \& Lees, A. C. (2021). Optimizing tropical forest bird surveys using passive acoustic monitoring and high temporal resolution

Milliken, W., Zappi, D., Sasaki, D., Hopkins, M., \& Pennington, R. T. (2010). Amazon vegetation: How much don't we know and how much does it matter? Kew Bulletin, 65(4), 691-709. https://doi.org/10.1007/s12225-0109236-x

Møller, A. P. (1991). Why mated songbirds sing so much: Mate guarding and male announcement of mate fertility status. The American Naturalist, 138, 994-1014. https ://doi.org/10.1086/285264

Moura, N. G., Lees, A. C., Aleixo, A., Barlow, J., Berenguer, E., Ferreira, J., .. Gardner, T. A. (2016). Idiosyncratic responses of Amazonian birds to primary forest disturbance. Oecologia, 180(3), 903-916. https://doi.org/10.1007/s00442-015-3495-z

Newson, S. E., Bas, Y., Murray, A., \& Gillings, S. (2017). Potential for coupling the monitoring of bush-crickets with established large-scale acoustic monitoring of bats. Methods in Ecology and Evolution, 8(9), 1051-1062. https://doi.org/10.1111/2041-210X.12720

Nicolau, A. P., Herndon, K., Flores-Anderson, A., \& Griffin, R. (2019). A spatial pattern analysis of forest loss in the Madre de Dios region, Peru. Environmental Research Letters, 14(12). https://doi.org/10.1088/17489326/ab57c3

Oksanen, J., Guillaume Blanchet, F., Friendly, M., Kindt, R., Legendre, P., McGlinn, D., Minchin, P. R., O’hara, R. B., Simpson, G. L., Solymos, P., Stevens, M. H. H., Szoecs, E., \& Wagner, H. (2019). vegan: Community ecology package. R package version 2.5-6. Retrieved from https:// CRAN.R-project.org/packa ge=vegan

Parker, T. (1991). On the Use of Tape Recorders in Avifaunal Surveys. The Auk: Ornithological Advances, 108(02), 443-444. https://doi.org/10.1093/auk/108.2.443

Penteriani, V. (2003). Breeding density affects the honesty of bird vocal displays as possible indicators of male/territory quality. Ibis, 145(3), 513-513. https://doi.org/10.1046/j.1474-919x.2003.01734.x

Phillips, O., Gentry, A. H., Reynel, C., Wilkin, P., \& Galvez-Durand B, C. (1994). Quantitative Ethnobotany and Amazonian Conservation. Conservation Biology, 8(1), 225-248. https://doi.org/10.1046/j.15231739.1994.08010225.x

Pillay, R., Fletcher, R. J., Sieving, K. E., Udell, B. J., \& Bernard, H. (2019). Bioacoustic monitoring reveals shifts in breeding songbird populations and singing behaviour with selective logging in tropical forests. Journal of Applied Ecology, 56(11), 2482-2492. https://doi.org/10.1111/1365-2664.13492

Pires, J.M., Prance, G. 1985. The vegetation types of Brazilian Amazon. In: Prance GT, Lovejoy TE, editors. Key Environment - Amazonia. New York (NY): Pergamon Press. p. 109-145.

R Core Team. (2019). R: A language and environment for statistical comput- ing. R Foundation for Statistical Computing. Retrieved from https:// www.R-proje ct.org/ 
Ralph, C. J., Sauer, J. R., \& Droege, S. (1995). Monitoring Bird Populations by Point Counts. The Journal of Wildlife Management, 61(4), 1453. https://doi.org/10.2307/3802161

Redford, K. H. (1992). The Empty Forest. BioScience, 42(No. 6 (Jun., 1992)), 412-422. https://doi.org/https://doi.org/10.2307/1311860

Rempel, R. S., Hobson, K. A., Holborn, G., Van Wilgenburg, S. L., \& Elliott, J. (2005). Bioacoustic monitoring of forest songbirds: interpreter variability and effects of configuration and digital processing methods in the laboratory. Journal of Field Ornithology, 76(1), 1-11. https://doi.org/10.1648/0273-8570-76.1.1

Rempel, R. S., Jackson, J. M., Van Wilgenburg, S. L., \& Rodgers, J. A. (2019). A multiple detection state occupancy model using autonomous recordings facilitates correction of false positive and false negative observation errors. Avian Conservation and Ecology, 14(2). https://doi.org/10.5751/ACE-01374-140201

Remsen, J. V, \& Parker III, T. A. (1983). Contribution of River-Created Habitats to Bird Species Richness in Amazonia. Biotropica, 15(3), 223-231.

Remsen, J. V. (1994). Use and Misuse of Bird Lists in Community Ecology and Conservation. The Auk, 111(1), 225-227. https://doi.org/10.2307/4088531

Remsen, J. V., \& Good, D. A. (1996). Misuse of Data from Mist-Net Captures to Assess Relative Abundance in Bird Populations. The Auk, 113(2), 381-398.

Robinson, S. K., \& Terborgh, J. (1997). Bird Community Dynamics along Primary Successional Gradients of an Amazonian Whitewater River. Ornithological Monographs, (48), 641-672. Retrieved from https://www.jstor.org/stable/40157559 primer of best practices. Biotropica, 50(6), 846-849. https://doi.org/10.1111/btp.12608

Rodriguez, A., Gasc, A., Pavoine, S., Grandcolas, P., Gaucher, P., \& Sueur, J. (2014). Temporal and spatial variability of animal sound within a neotropical forest. Ecological Informatics, 21, 133-143. https://doi.org/10.1016/j.ecoinf.2013.12.006

Sánchez-Cuervo, A. M., de Lima, L. S., Dallmeier, F., Garate, P., Bravo, A., \& Vanthomme, H. (2020). Twenty years of land cover change in the southeastern Peruvian Amazon: implications for biodiversity conservation. Regional Environmental Change, 20(1). https://doi.org/10.1007/s10113-020-01603-y

Schulenberg, Thomas S., et al. Birds of Peru: Revised and Updated Edition. Revised and Updated Edition ed. Princeton University Press, 2010. Project MUSE muse.jhu.edu/book/30246.

Scott, J. M., S. Mountainspring, F. L. Ramsey, and C. B. Kepler. 1986. Forest bird communities of the Hawaiian Islands: their dynamics, ecology, and conservation. Stud. Avian Biol. No. 9.

Sekercioglu, Ç. H., Ehrlich, P. R., Daily, G. C., Aygen, D., Goehring, D., \& Sandí, R. F. (2002). Disappearance of insectivorous birds from tropical forest fragments. Proceedings of the National Academy of Sciences of the United States of America, 99(1), 263-267. https://doi.org/10.1073/pnas.012616199 
Shonfield, J., \& Bayne, E. M. (2017). Autonomous recording units in avian ecological research: current use and future applications. Avian Conservation and Ecology, 12(1). https://doi.org/10.5751/ace-00974-120114

Socolar, J. B., Valderrama Sandoval, E. H., \& Wilcove, D. S. (2019). Overlooked biodiversity loss in tropical smallholder agriculture. Conservation Biology, 33(6), 1338-1349. https://doi.org/10.1111/cobi.13344

Stevens, H. C., Metz, E. M., Saboya Del Castillo, P., Alván, J. D., \& Bowler, M. T. (2019). Use of autonomous audio recordings for the rapid inventory of birds in the white-sand forests of the Peruvian Amazon. Journal of Field Ornithology, 90(1), 70-79. https://doi.org/10.1111/jofo.12279 Dynamics of Forest Fragments Project. The Condor, 122, 1-15. https://doi.org/10.1093/condor/duaa005

Stouffer, P. C., Jirinec, V., Rutt, C. L., Bierregaard, R. O., Hernández-Palma, A., Johnson, E. I., ... Lovejoy, T. E. (2020). Long-term change in the avifauna of undisturbed Amazonian rainforest: ground-foraging birds disappear and the baseline shifts. Ecology Letters. https://doi.org/10.1111/ele.13628

Sugai, L. S. M., \& Llusia, D. (2019). Bioacoustic time capsules: Using acoustic monitoring to document biodiversity. Ecological Indicators, 99(December 2018), 149-152. https://doi.org/10.1016/j.ecolind.2018.12.021

Sullivan, B. L., Wood, C. L., Iliff, M. J., Bonney, R. E., Fink, D., \& Kelling, S. (2009). eBird: A citizen-based bird observation network in the biological sciences. Biological Conservation, 142(10), 2282-2292. https://doi.org/10.1016/j.biocon.2009.05.006

Tegeler, A. K., Morrison, M. L., \& Szewczak, J. M. (2012). Using extended-duration audio recordings to survey avian species. Wildlife Society Bulletin, 36(1), 21-29. https://doi.org/10.1002/wsb.112

Terborgh, J., Robinson, S. K., Parker III, T. A., \& Munn, C. A. (1990). Structure and Organization of an Amazonian Forest Bird Community. Ecological Monographs, 60(2), 213-238.

Tuomisto, H., Ruokolainen, K., Kalliola, R., Linna, A., Danjoy, W., \& Rodriguez, Z. (1995). Dissecting amazonian biodiversity. Science, 269(5220), 63-66. https://doi.org/10.1126/science.269.5220.63

United Nations General Assembly. Transforming our world: the 2030 Agenda for Sustainable Development (United Nations, New York, 2015). Available at https://sustainabledevelopment.un.org/content/documents/21252030\%20Agenda\%20for\%20Sustainable\%20D evelopment $\% 20$ web.pdf

Van Wilgenburg, S. L., Sólymos, P., Kardynal, K. J., \& Frey, M. D. (2017). Paired sampling standardizes point count data from humans and acoustic recorders. Avian Conservation and Ecology, 12(1). https://doi.org/10.5751/ace-00975-120113

Venier, L. A., Holmes, S. B., Holborn, G. W., McIlwrick, K. A., \& Brown, G. (2012). Evaluation of an automated recording device for monitoring forest birds. Wildlife Society Bulletin, 36(1), 30-39. https://doi.org/10.1002/wsb.88 
1014

1015

1016

1017

1018

1019

1020

1021

1022

1023

1024

1025

1026

1027

1028

1029

1030

1031

1032

1033

1034

1035
Whitworth, A., Beirne, C., Rowe, J., Ross, F., Acton, C., Burdekin, O., \& Brown, P. (2015). The response of faunal biodiversity to an unmarked road in the Western Amazon. Biodiversity and Conservation, 24(7), 1657-1670. https://doi.org/10.1007/s10531-015-0883-y

Wilson, K. A., et al. (2016). Conservation Research Is Not Happening Where It Is Most Needed. PLoS Biology, 14(3), 1-5. https://doi.org/10.1371/journal.pbio.1002413

Wolfe, J. D., Stouffer, P. C., Mokross, K., Powell, L. L., \& Anciaes, M. M. (2015). Island vs. countryside biogeography: An examination of how Amazonian birds respond to forest clearing and fragmentation. Ecosphere, 6(12), 1-14. https://doi.org/10.1890/ES15-00322.1

Woltmann, S. (2005). Patterns of daily temporal variation in detectability of forest birds in Bolivia. Ornitologia Neotropical, 16(3), 337-346.

Woltmann, S., Kreiser, B. R., \& Sherry, T. W. (2012). Fine-scale genetic population structure of an understory rainforest bird in Costa Rica. Conservation Genetics, 13(4), 925-935. https://doi.org/10.1007/s10592-0120341-2

Wood, C.M., Kahl, S., Chaon, P., Peery, M.Z., Klinck, H. (2021). Survey coverage, recording duration and community composition affect observed species richness in passive acoustic surveys. Methods in Ecology and Evolution 12(5), 885-896. https://doi.org/10.1111/2041210X.13571 